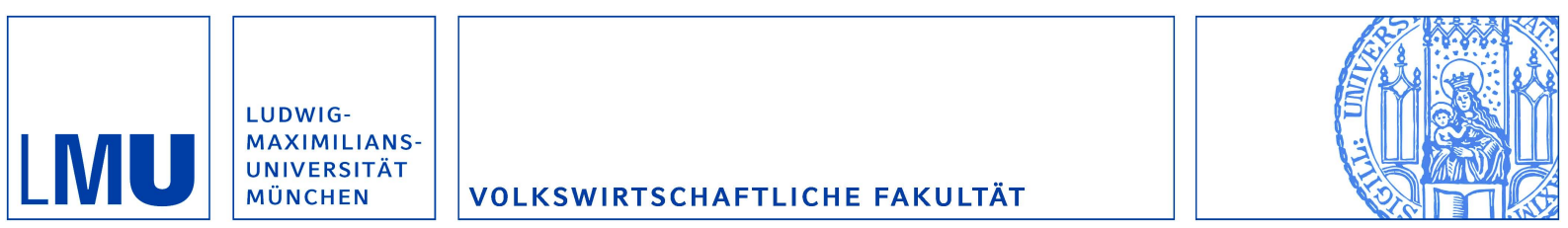

Kocher, Martin G. and Luhan, Wolfgang J. and Sutter, Matthias:

Testing a forgotten aspect of Akerlof's gift exchange hypothesis: Relational contracts with individual and uniform wages

Munich Discussion Paper No. 2012-11

Department of Economics

University of Munich

Volkswirtschaftliche Fakultät

Ludwig-Maximilians-Universitäł München

Online at https://doi.org/10.5282/ubm/epub. 12816 


\title{
Testing a forgotten aspect of Akerlof's gift exchange hypothesis: Relational contracts with individual and uniform wages ${ }^{\#}$
}

\author{
Martin G. Kocher ${ }^{*}$, Wolfgang J. Luhan ${ }^{+}$, and Matthias Sutter ${ }^{\S}$
}

\begin{abstract}
Empirical work on Akerlof's theory of gift exchange in labor markets has concentrated on the fair wage-effort hypothesis. In fact, however, the theory also contains a social component that stipulates that homogenous agents that are employed for the same wage level will exert more effort, resulting in higher rents and higher market efficiency, than agents that receive different wages. We present the first test of this component, which we call the fair uniform-wage hypothesis. In our laboratory experiment, we establish the existence of a significant efficiency premium of uniform wages. However, it is not the consequence of a stronger level of reciprocity by agents, but of the retrenchment of sanctioning options on the side of principals with uniform wages. Hence, implementing limitations to contractual freedom can have efficiency-enhancing effects.
\end{abstract}

This version: 03 March 2012

JEL classification: C72, C91, C92, D21, J31, J50

Keywords: gift exchange, multiple agents, uniform contracts, collective wage, experiment

\footnotetext{
\# We would like to thank Martin Dufwenberg, Ernst Fehr, Jana Jarecki, Oliver Kirchkamp, Stephan Kroll, Tibor Neugebauer, Louis Putterman, Ferdinand von Siemens and seminar participants in Amsterdam, Gothenburg, Innsbruck, Magdeburg, Milan, Zurich and at the ESA Meetings, IMEBE, the Austrian Economic Association Annual Meeting, the European Association of Labor Economists Annual Meeting, the IAREP/SABE Congress as well as the European Economic Association's Annual Meeting for very helpful comments. We are grateful to the Center for Experimental Economics at the University of Innsbruck (sponsored by Raiffeisen-Landesbank Tirol) the Austrian Science Foundation - FWF (Project P16617) and the Tiroler Wissenschaftsfonds (TWF) for financial support.

" University of Munich, University of Gothenburg, and CESifo Munich. Address: University of Munich, Department of Economics. Geschwister-Scholl-Platz 1, D-80539 Munich, Germany. martin.kocher@lrz.unimuenchen.de

${ }^{+}$University of Bochum. Address: University of Bochum, Department of Economics. Universitaetsstr. 150, D-44801 Bochum, Germany. wolfgang.luhan@ ruhr-uni-bochum.de

${ }^{\S}$ Corresponding author. University of Innsbruck, University of Gothenburg, IZA Bonn, and CESifo Munich. Address: University of Innsbruck, Department of Public Finance. Universitätsstrasse 15, A-6020 Innsbruck, Austria.matthias.sutter@uibk.ac.at
} 


\section{Introduction}

In many economic interactions between a principal and an agent, contractual obligations can only be specified imprecisely, and hence it is difficult for third parties to guarantee contract enforcement. As a consequence, with selfish decision makers only minimal levels of contract fulfillment can be achieved, and potential gains from trade are forgone. In his seminal paper on incomplete contracts in labor markets, Akerlof (1982) analyzes such situations. He describes labor contracts as partial gift exchange and lays the foundation of the fair wage-effort hypothesis: agents' efforts depend not only on the monetary wage but also on the perceived fairness of the wage, and as a consequence, it may be optimal for principals to pay more than the market-clearing wage (see also Gintis, 1976; Akerlof and Yellen, 1988, 1990). Empirically, the resulting positive wage-effort relationship and concomitant involuntary unemployment have been observed both in the laboratory (e.g., Fehr et al., 1993, 1997, 1998a,b; Fehr and Falk, 1999; Charness, 2000, 2004; Hannan et al., 2002; Brown et al., 2004) and in the field (e.g., Gneezy and List, 2006; Bellemare and Shearer, 2009; Henning-Schmidt et al., 2010; Kube et al., 2012). ${ }^{1}$

The existing literature has largely disregarded that Akerlof's (1982) gift exchange hypothesis actually consists of two main aspects: Workers not only reciprocate to above market-clearing wages by providing higher effort levels (the well-known fair wage-effort hypothesis), but they also "acquire sentiment for each other" (p. 543). "As a consequence of worker sentiment for one another, the firm cannot deal with each worker individually, but rather must at least to some extent treat the group of workers with the same norm, collectively" (p. 544).

This paper provides an experimental test of this neglected, second aspect of gift exchange that we call the fair uniform-wage hypothesis. To the best of our knowledge, we are the first to perform such a direct empirical test of Akerlof's (1982) conjecture regarding mutual sentiments. The fair uniform-wage hypothesis stipulates that homogenous agents that are employed for the same wage level will exert more effort, resulting in higher rents, than agents that receive different wages. In order to test this hypothesis we extend the usual experimental setting that is based on a one-on-one matching of principals and agents to a multiple agents design.

\footnotetext{
${ }^{1}$ Excellent recent overviews are provided by Charness and Kuhn (2010) and Cooper and Kagel (forthcoming), with the latter embedding gift exchange games in the broader context of studies on otherregarding preferences.
} 
In our experiment, principals interact with agents on a continuous posted offer market. Principals have identical profit functions, and agents do not differ with respect to their cost-of-effort function and productivity. In each period principals can offer a wage level privately to any of the agents or, alternatively, publicly to all agents on the market (a feature pioneered by Brown et al., 2004, and Kirchsteiger et al., 2005). Agents can accept any offer, but are restricted to a single contract in a given period. Principals are allowed to employ a maximum of three agents in each period, and labor demand is the short side of the market. After principals and agents have been matched through the market, agents have to choose an effort level. The higher the effort level, the higher is the cost for the agent, but so is also the principal's profit. $^{2}$

We introduce two straightforward experimental treatments to this modified principalagent game that allow for an exogenous variation of the wage distribution within the firm and, hence, for a direct test of the fair uniform-wage hypothesis: (i) an individual contract treatment, henceforth abbreviated by $I C$, in which principals can, but need not, employ workers for identical contracts in a given period, and (ii) a uniform contract treatment, henceforth $U C$, in which principals are forced to employ all agents under the same conditions in a given period. More specifically, in the UC treatment, the first accepted contract simply serves as a blueprint for all other contracts that a principal can offer in a given period. In other words, she ${ }^{3}$ is bound to offer the same contract to all agents in the firm. This can be interpreted as an exogenous non-discriminatory clause, whose effects can be studied in treatment UC. All other features of the markets are kept identical across treatments.

Our empirical results indicate that principals almost never offer identical contracts to a priori identical agents if they are allowed to differentiate individually (in IC), and that the number of uniform contracts within firms does not increase with increasing experience of principals. The introduction of uniform (standardized) contracts on the firm level has a significant and economically relevant effect on market parameters in UC: It increases average wages, effort levels, and market efficiency. We empirically corroborate the fair uniform-wage hypothesis. However, the efficiency premium of uniform wages is not a consequence of agents becoming more reciprocal in their effort choice in response to a given (uniform) wage level. Rather, the efficiency-enhancing effect is the consequence of

\footnotetext{
${ }^{2}$ Of course, the wage can also be interpreted as a price and the effort as a quality level on an incomplete product market.

${ }^{3}$ We posit throughout the paper that the principals are female and the agents are male.
} 
eliminating a tendency of principals to over-differentiate contracts within their firm - if they are allowed to - compared to the ex-post optimum. Making differentiation impossible leads to higher average wages, an increase in average effort levels and thus higher market efficiency.

These results imply that Akerlof's (1982) emphasis on adding a social component to his description of gift exchange seems crucial when it comes to efficiency. The total efficiency rent from gift exchange is the combination of the individual fair wage-effort relationship between a single principle and a single agent plus the fair uniform-wage relationship in a multiple-agents framework. In other words, limitations to contractual freedom - here, a non-discriminatory wage legislation targeted on the firm level - can have efficiency-enhancing effects and can thus be welfare-improving.

Although there are several papers that study aspects or components of the contract offer made by a principal to an agent aside from the individual wage (e.g., Irlenbusch and Sliwka, 2005, who let the principal decide whether to use a piece rate; Falk and Kosfeld, 2006, who implement forcible restrictions on the agent's choice set; Fehr et al., 2007, who use non-enforceable promises by the principal), a real test of the fair uniform-wage hypothesis has to implement a multi-worker firm, i.e. a principal that can employ several agents. There is only a handful of existing experiments which extend the usual one-on-one setting that is either implemented bilaterally (e.g., Fehr et al., 1998b) or through a labor market (e.g., Brown et al., 2004) to a one-to-many setup. We are not aware of any direct test of the fair uniform-wage hypothesis, so far, because recent papers in this literature focus on social comparison in itself. ${ }^{4}$

Cabrales and Charness (2011) study contracts offered simultaneously by one principal to two differently productive agents in a hidden information context. Contracts have to be accepted by both agents, reflecting a situation where contracts must be negotiated with a union and, then, be approved by the workers. They observe that rejection of contract menu offers depends on how discriminating the offers are.

Charness and Kuhn (2007) test predictions from social preference models on whether the behavior of two workers in the same firm is affected by the respective co-worker's wage. Contrary to their expectations of a wage compression effect, their results indicate

\footnotetext{
${ }^{4}$ Results based on a survey of managers by Bewley (1999) are an exception. The managers emphasize the importance of non-discriminatory contracting on internal harmony and morale, but a survey is only partly able to compare situations that differ with regard to discrimination and to assess the effects of discrimination on reciprocity and efficiency.
} 
that workers' effort choices are highly sensitive to their own wages, but largely unresponsive to co-workers' wages. Somewhat in contrast to Charness and Kuhn (2007), Falk and Ichino (2006) show that co-workers' efforts matter in a real-effort experiment. Gächter et al. (2010), looking at wage and effort information, find that co-workers' wages per se have no effect. When a principal pays different wages to two workers, the coworker's effort decision is ignored. However, worker behavior is affected when both pieces of social information are provided: higher wages generate higher effort when one's co-worker exerts high effort, but does not change behavior when the co-worker contributes little or no effort. In contrast to the above contributions, we do not focus on the effects of social information on the wage-effort relationship. We assess the effects of exogenously imposed uniform wages within the firm $^{5}$ on reciprocity and on important market parameters.

Obviously, it is difficult to judge from real-world observation whether the reluctance of employers to offer uniform contracts to homogeneous workers is a consequence of a general resentment of principals against "collective" contracts, of some important behavioral effects not captured in economic models that could speak against uniform contracts across agents, or of possible other reasons. It is a difficult task to compare the effects of individualized wages with those of uniform wages within a firm based on field data, because disentangling the effects of unionization, measuring the degree of contractual incompleteness and assessing the extent of agent heterogeneity is not easy. ${ }^{6}$ A possible alternative route that we pursue in this paper is conducting laboratory experiments. Experiments allow focusing on the mere effects of contract standardization in comparison to individual contracts.

The remainder of the paper is organized as follows: Section 2 presents the details of the market model and our experimental design, and Section 3 introduces our theoretical

\footnotetext{
${ }^{5}$ The most widely studied regulations are restrictions on a lower-boundary wage level, with Brandts and Charness (2004) finding negative consequences on voluntary effort provision, while Fehr et al. (2006) and Owens and Kagel (2010) report that they can have positive effects. Abeler et al. (2010) study a "reverse" gift-exchange setting, in which two agents first choose efforts and then the principal sets a wage. In one of their treatments principals can only set a single wage for both agents; in the second treatment wages can be set individually. If agents provide different levels of effort, equality is obviously unfair, and forcing principals to offer a single wage discourages the provision of high efforts, which is what Abeler et al. (2010) find.

${ }^{6} \mathrm{We}$ are not aware of field evidence on our research question. Again, the literature mainly focuses on the effects of social comparison (e.g., Galizzi and Lang, 1998; Neumark and Postlewaite, 1998; Clark et al., 2008, 2009). There is also an extensive literature on the effects of unionization on labor markets (see, for instance, Freeman, 1982, Card et al. 2004; Kahn, 2012), but such approaches cannot disentangle the joint effects of unionization and wage standardization.
} 
predictions. Section 4 provides the main experimental results, while Section 5 discusses why the fair uniform-wage hypothesis is reflected in the data. Section 6 concludes the paper and discusses its implications.

\section{Model and experimental design}

\subsection{The principal-agent model with multiple agents in the experiment}

In each session, four subjects were assigned to the role of principals and 16 to the role of agents. Each participant received a unique identification (ID) number that remained the same throughout the experiment. ${ }^{7}$ Therefore, participants, though anonymous, were identifiable during the whole experiment, and repeated interaction was possible. Each period $t \in\{1,2, \ldots, T\}$ consisted of two stages: (i) a three-minute trading phase and, (ii) an effort-determination phase. Only principals could offer contracts $\{w, \tilde{e}\}$ in the trading phase, where $w$ denotes the wage rate and $\tilde{e}$ the desired effort level. In the experiment, $w$ had to be an integer from the interval $[1,100]$ and $\tilde{e}$ from $[1,10]$.

There was no limit for a principal regarding the number of contract offers within one trading period. ${ }^{8}$ Agents could accept any, but at most one, offer in real time, but could not offer contracts to principals themselves. As soon as three contracts of a particular principal were accepted, all standing contract offers of this principal were deleted instantaneously. The duration of each contract was always one period. Thus, each period started with all the agents being unemployed as the default. After the trading phase, those agents who had accepted a contract had to submit an effort level $e$ out of the set of feasible effort levels $\{1,2, \ldots, 10\}$. The desired effort level of the principal $(\tilde{e})$ was not binding for the agent, making the contract incomplete.

Suppressing the time indices for convenience, in each period the monetary payoffs for the agent were determined as follows:

$$
\pi_{A}= \begin{cases}w-\mathrm{c}(\mathrm{e}) & \text { if a contract was concluded } \\ 5 & \text { if no contract was concluded }\end{cases}
$$

The principal's monetary payoff was given by:

\footnotetext{
${ }^{7}$ The basic setup follows Brown et al. (2004). We extended their design to allow for multiple agents and our treatment variation.

${ }^{8}$ It was permitted to offer the same contract more than once.
} 


$$
\pi_{P}= \begin{cases}\alpha \cdot\left(\sum_{i=1}^{N} e_{i}\right)-\left(\sum_{i=1}^{N} w_{i}\right) & \text { if a contract was concluded } \\ 0 & \text { if no contract was concluded }\end{cases}
$$

where $\alpha>0$ is a productivity parameter and $N \leq 3$ represents the number of employed agents. In the experiment, we set $\alpha=10$. Agents had to bear a cost of effort denoted by $c(e)$ that was increasing in effort with increasing marginal costs according to the schedule in Table 1, which is commonly used in the literature. Obviously, the efficient effort level was the maximum effort $e=10$, as the marginal costs of effort were at most 3 , and the marginal revenue was always equal to $\alpha=10$. If an agent did not conclude a contract, he received a lump-sum payment of 5 tokens (the experimental currency unit).

\section{Insert Table 1 around here}

An important feature of the trading phase concerns the way contract offers could be submitted. Principals could decide whether they wanted to make private or public offers. For private offers, a principal had to enter the agent's ID number with whom she wanted to trade. Only this agent was informed about the offer. Public offers were visible to all agents as well as to all other principals on the market. Private and public offers could be made concurrently during the trading phase. Payoff functions, the cost of effort, the number of principals and agents within a session, and the number of periods were common knowledge.

Note that it was easy to establish a long-term relationship by offering contracts privately to the agent with the same ID number in subsequent periods. Principals were informed about the IDs of agents that were already employed or still unemployed at any time during the trading phase. Standing offers, whether private or public, could be accepted at any time during the trading phase by unemployed agents.

\subsection{Experimental treatments}

We implemented two treatments: In the individual contract treatment (IC), principals could offer any contract within the parameter range to any agent privately or over the market. There were no other restrictions on contract offers. While in the uniform contract treatment (UC) principals could also offer different contracts, they were facing one crucial restriction that constitutes the treatment variation: A principal's first accepted contract 
became automatically the standard contract for all subsequent contracts within a given period in her firm. In other words, the principal was legally bound to offer the same contract (as the first one being accepted) to all further (potential) employees in the current period. As soon as the first contract of a specific principal was accepted, all standing contract offers of this principal that differed from the accepted contract were deleted.

There are several reasons for implementing the UC treatment in this way. First, we did not want to impose any standard contract ourselves because our main interest is in the endogenous evolution of wages and effort levels, given that contracts have to be uniform. Second, we wanted to avoid a rather complicated collective bargaining procedure between principals and agents within a firm that would have rendered the direct comparison between the two treatments impossible. While our setup is clearly a simplification of reality, and there are other possible ways to implement uniform contracts within a firm, we believe that we have chosen a natural starting point with the highest level of experimental control. One obvious alternative - letting principals offer only one blueprint contract from the start of each trading phase on - was discarded by us because it would have differed too profoundly from the IC treatment. Note finally that the payoff functions are completely identical for the two treatments, both for principals and agents.

\subsection{Laboratory protocol}

Each session consisted of 15 identical periods. ${ }^{9}$ Upon arrival subjects received detailed instructions (given in the Appendix). After an experimenter read them aloud, subjects were asked to solve several exercises (also provided in the Appendix) in order to ensure that they fully understood the rules and the consequences of every action they were to take in the experiment. After having publicly solved the exercises, we answered any remaining questions privately before starting the experiment. At the end of each period, subjects were informed about contracts, payoffs and ID numbers of the principal and all employed agents within their firm. Thus, agents were not only provided with information concerning their contracts, but also received information regarding the contracts of their co-agents as well

\footnotetext{
${ }^{9}$ Two practice periods without financial incentives were played in each session before the start of the experiment in order to make subjects familiar with the market environment. ID numbers were reshuffled after the practice periods to avoid any transfer of reputation effects from the practice phase to the experiment. Subjects were fully aware of this procedure.
} 
as the total payoff of the principal. ${ }^{10}$ They were, however, never informed about the actually chosen effort levels of their co-workers. Principals received detailed information on all contracts within their firm, including all effort levels of their agents. At the end of the experiment subjects were asked to fill in a short questionnaire regarding socioeconomic characteristics and were informed about their total earnings converted into euro at the pre-announced conversion rate of experimental tokens into euro. The money was paid privately and in cash.

The experiment was implemented using the software z-tree (Fischbacher, 2007). For each treatment five sessions were run, with none of the 199 subjects participating in more than one of the 10 sessions. ${ }^{11}$ Participants were students studying different subjects at the University of Innsbruck. Sessions lasted about 90 minutes, and participants earned on average $€ 16.57$.

\section{Predictions}

Let us start by assuming that all players are risk-neutral, rational and selfish maximizers of monetary profits, and that this is common knowledge. Since the interaction horizon is finite and known by all players, we can confine the analysis to one period and apply backward induction. Agents would choose the lowest permissible effort level $e=1$ because effort exertion is costly. As a consequence, principals will offer only the reservation wage $(w=5)$, and the desired effort is obviously irrelevant. ${ }^{12}$ Twelve trades would take place, i.e. each principal should employ the maximum of three agents, and four agents should remain unemployed. The resulting subgame-perfect equilibrium is the same for the IC and the UC treatment. Thus, according to standard theory we should not observe any difference in the market outcomes between the two treatments.

The theoretical solution based on the assumption of common knowledge of rationality and selfishness entails a considerable efficiency loss for our market parameters. In equilibrium $\pi_{A}=5$ and $\pi_{P}=3 \cdot 10-3 \cdot 5=15$. Within a firm, this amounts to $3 \pi_{A}+\pi_{P}=30$. Since for the permissible parameter range marginal costs of effort are

\footnotetext{
${ }^{10}$ In contrast to the literature on wage comparison, we wanted to avoid any direct influence und decided to inform agents about their co-workers wages only after effort submission.

${ }^{11}$ In one UC session, there were only 15 instead of 16 agents due to low show-ups.

${ }^{12}$ For $\mathrm{w}=5$ agents are indifferent to accept the offer. Since we require the wage rate to be an integer value, $\mathrm{w}=6 \mathrm{can}$ also be optimal. From an empirical perspective, the difference is of minor importance.
} 
always lower than marginal revenues, the social optimum would be reached at the maximum effort level and the maximum number of employed agents. Wages can be disregarded as they only constitute a reallocation of the generated rents. Given our parameters, $3 \pi_{A}+\pi_{P}=246$ is the Pareto-optimum. Again, there is no difference between the two treatments.

We now consider the case where rationality or selfishness of all players is not common knowledge (e.g., Kreps et al., 1982; Fudenberg and Maskin, 1986; Rabin, 1993; Levine, 1998; Fehr and Schmidt, 1999; Bolton and Ockenfels, 2000; Charness and Rabin, 2002; Falk and Fischbacher, 2006). Given the plethora of equilibria in the game, we keep our theoretical analysis informal because a more formal approach would not add much in terms of deriving clear-cut predictions. Depending on the principal's beliefs over the distribution of types (e.g., selfish and non-selfish ones), a principal will either offer trust contracts (i.e. contracts with higher than minimal $w$ and $\tilde{e}=10$ ) or reservation wage contracts (i.e. contracts with $w=5$ and any $\tilde{e}$ ) in the stage game. Hence, in the first period, trust contracts (subscript $t r$ ) will be offered by a principal when she expects a profit larger than 15 , i.e. if $E\left[\pi_{P, t r}\right]>15$ or, equivalently, $\alpha \cdot\left(\sum_{i=1}^{N} E\left[e_{i}\right]\right)>\left(\sum_{i=1}^{N} w_{i}\right)+15$. There is no point in concluding different contracts with different agents because there is no way for principals to sort agents according to their individual type through the contract offer. ${ }^{13}$

While it cannot be part of an equilibrium strategy of principals to conclude different contracts with her agents in the first period and, thus, there should not be any difference between the IC treatment and the UC treatment, theoretical predictions change for periods $t>1$, because principals can update their beliefs about agents' reciprocity levels at the end of each period. Rewarding compliant agents (those that provide effort $e \geq \tilde{e}$ ) and punishing shirkers (those that provide effort $e<\tilde{e}$ ) by not re-employing them or offering them less favorable contract terms (a reservation wage contract) in the subsequent period can obviously be part of an equilibrium strategy. Such punishment and reward is made more difficult to enforce in the UC treatment because principals cannot target individual

\footnotetext{
${ }^{13}$ Note that reputation building can be a profitable strategy in our setup even for completely selfish agents. Using the model of Fehr and Schmidt (1999), Brown et al. (2004) show for the one-on-one principal-agent matching that if sufficiently many fair subjects are present, there is an equilibrium in which all agents exert high efforts in the first 14 periods, while in period 15 only the fair-minded agents submit non-minimal effort levels. This basic rationale also applies to a multiple-agent setting (see Kocher and Strasser, 2012), and therefore to our framework. The underlying idea is straightforward: Since the existence of fair agents makes it profitable for principals to offer generous contracts, selfish agents have an incentive to disguise their real type and mimic the fair agents until the penultimate period.
} 
agents properly. In UC, the only punishment threat a principal has is not reemploying shirking agents, and any reward has to go to all agents within the firm (also to those that have not reciprocated in the previous period or those who have not been employed before).

We summarize these arguments in the following predictions:

Prediction 1: Principals should employ all their agents under identical contracts in the first period. Thus, there should not be any difference between IC and UC in the first period.

Prediction 2: If decision-makers are payoff-maximizers and this is common knowledge, Prediction 1 extends to the entire interaction horizon. Under more general preferences or without the assumption of common knowledge, however, heterogeneous contracts within the firm can be part of an equilibrium strategy in the IC treatment. Consequently, there might be a difference in market outcomes between the two treatments from period 2 on.

Any combination of contracts in UC is also feasible in IC, i.e. principals in IC can always copy behavior of principals in UC. In other words, the action space of principals in UC is simply a subset of the action space of principals in IC. Hence, principals in IC should fare at least as good as principals in UC. However, as soon as one gives up the common knowledge assumption, we are facing a multitude of equilibria. Thus, equilibrium selection might work differently in the two treatments. Nevertheless, we think it is justified to formulate Prediction 3 as a working hypothesis.

Prediction 3: Principals in IC should fare at least as good as principals in UC.

In contrast to predictions 1 to 3 - which suggest no difference between IC and UC the fair uniform-wage hypothesis of Akerlof (1982) leads to an alternative prediction, which is our final one:

Prediction 4: Uniform wages lead to significantly higher levels of voluntary effort provision and, consequently, higher levels of overall efficiency. 


\section{Main experimental results}

The main descriptive results of the experiment are presented in Table 2 to which we will frequently refer to in this section. We display the overall means with standard deviations in parentheses. All observations are measured in experimental tokens and percent, respectively. When comparing the two treatments, we employ two-sided Mann-WhitneyU-tests. ${ }^{14}$ Significance tests have been conducted on the mean values of each experimental session (with 20 market participants each). This is the most conservative approach because it uses five independent observations per variable for each treatment.

\section{Insert Table 2 around here}

\subsection{Wages and effort levels}

It becomes immediately obvious that several important market variables are significantly different across treatments, and that the difference goes in the opposite direction of Prediction 3. Wages are by $29.71 \%$ higher in the UC treatment than in IC, which is statistically significant on conventional levels. Figure 1 shows that mean wages in the UC treatment are in all 15 periods well above those of the IC treatment, with the notable exception of the very first period (consistent with Prediction 1). In both treatments wages display an upward trend over time that appears to be stronger in UC than in IC. While UCwages are well above 40 tokens from the fourth period on, reaching their peak of 55.15 in period 13, the IC-wages range between 31 and 41. We find the common endgame-effect, but wages stay above 40 and 30 tokens, respectively. ${ }^{15}$

\section{Insert Figure 1 and Figure 2 around here}

Average effort levels in Figure 2 are also higher in markets with uniform contracts than in markets with individual contracts. The average effort difference of $29.08 \%$ between the two treatments matches the $29.71 \%$ average wage difference almost perfectly. Again,

\footnotetext{
${ }^{14}$ Applying two-sided t-tests produced qualitatively the same results.

15 There is no significant difference between the first contract offered by a principal and the first accepted contract. Hence our findings carry over from realized contracts to offered contracts.
} 
the treatment difference is significant; we also observe an upward trend and a rather strong endgame effect. In sum, the results for wages and efforts support Prediction 4.

\subsection{Market efficiency and the share of private and public offers}

Market efficiency is obviously one of the most important variables in our analysis, because it concerns the heart of the fair uniform-wage hypothesis. With higher wages and efforts in $\mathrm{UC}$, and unemployment rates almost equal to those in IC, it is clear that the overall market efficiency is significantly higher in UC than in IC. The first row of Table 2 displays aggregate mean payoffs per period generated within a market, i.e. token earnings of all 20 players. In UC, these payoffs are on average 124.96 tokens or $23.68 \%$ higher than in IC. While in IC only $52 \%$ of the maximal efficiency is achieved, it is $65 \%$ in UC. Figure 3 shows average profits per subject in each single period, and they are always higher in UC than in IC. Actually, both principals and agents earn more in UC than in IC, but the difference is only significant for agents, because the variance of payoffs is much larger among principals than among agents.

\section{Insert Figures 3 and 4 about here}

Another significant difference between the two treatments concerns the share of private offers. The number of private offers is weakly significantly higher in UC than in IC (see Table 2). Figure 4 shows the time trend of private offers. Targeting specific agents in order to induce higher levels of effort seems to be one of the differences that the institution of uniform contracts causes. However, overall tenure at the same firm is not significantly longer in UC (see Table 2), although higher on average in all but two periods. Yet, we find a significant treatment difference in the likelihood with which all three workers in period $t$ are re-employed through private offers from the same principal also in period $t+1$. This happens in $41 \%$ of cases in UC, but only in $22 \%$ of cases in IC ( $p<0.01 ; \chi^{2}$-test).

\subsection{Reciprocity}

Figure 5 provides an overview of the level of reciprocity. The following parametric regression analysis basically reproduces the general pattern conveyed by the figure and our findings based on non-parametric statistics, but it also offers new insights. In Table 3 we 
report a Tobit estimation with the effort level as the dependent variable. ${ }^{16}$ We take into account the censoring of effort levels at $e=1$ and $e=10$ and use session fixed effects.

\section{Insert Table 3 and Figure 5 around here}

The first model (model 1) accounts for the following independent variables: wage, period and period squared, a dummy for private offers, and a dummy for the UC treatment. As expected, wages and the use of private contracts have a significantly positive impact on efforts chosen. The variables period and period squared account for a supposedly nonlinear time trend in all estimated models. Indeed, the time trend describes an inverted Ushape, with efforts rising in earlier periods and declining later on.

If we include the tenure of the relationship (model 2) between a principal and an agent as an independent variable, the significance levels of all other variables remain unchanged, and the magnitude of the effects remains similar, suggesting that a potential endogeneity bias is at best small. The variable itself is, as expected, highly significant.

The UC-dummy in models 1 and 2 shows the treatment differences in overall effort levels. It fails significance in model 1 , and is even significantly negative in model 2 , when taking tenure into account. Next, we estimate the sensitivity of efforts on wages for the two treatments separately. To this end, we introduce an interaction dummy variable called $U C^{*}$ wage in models 3 and 4 that captures the slope of the wage-effort function. These models show that the introduction of this interaction variable renders the pure treatment dummy, controlling for the wage level, significantly negative, although the results for all other variables remain almost unchanged. The coefficient for the interaction dummy itself is not significant. ${ }^{17}$

Our findings regarding important market characteristics are qualitatively and often even quantitatively in line with the results of Brown et al. (2004). ${ }^{18}$ Although they analyze a one-on-one gift exchange market and they only have seven principals and ten agents on a

\footnotetext{
${ }^{16}$ Using a Poisson-regression leads to the same insights. Results are available upon request.

${ }^{17}$ Including desired efforts as an independent variable does not change our conclusions, either. Since its behavioral effect on actually chosen efforts is, however, quite strong, it slightly affects the magnitude of the coefficients for the wage level (results are available upon request). Co-agents' wages and wage differentials within a firm cannot (and actually do not) have an impact because agents receive information on them only after they have decided on effort levels.

${ }^{18}$ We were able to compare all market variables, even those not reported in Brown et al. (2004), because the authors provided us with their raw data, for which we are very grateful.
} 
market, which makes it impossible to compare the two experiments directly, it is a reassuring fact that the results from different setups exhibit very similar characteristics. ${ }^{19}$

\subsection{Do principals in the IC treatment offer identical contracts?}

Here we analyze whether principals in the IC treatment voluntarily offer identical contracts to their agents in the first period, as we hypothesized based on both standard and more general preferences (see Prediction 1). We find that only $20 \%$ of all principals in the IC treatment offer homogeneous contracts to their employees in the first period, in which there cannot be any sanctioning motive in the contract offer. Across all 15 periods, only in $13 \%$ of cases principals offer identical contracts. This refutes Prediction 1 and the part of Prediction 2 that was based on standard payoff-maximizing preferences with the common knowledge assumption.

While we refute the hypothesis of principals offering uniform wages voluntarily, the underlying intuition - namely that principals should offer identical contracts to their agents in any given period - might still have been correct. In order to investigate that, we analyze whether those principals who offer identical contracts in IC are more successful than their peers in the IC treatment and, thus, statistically indistinguishable from principals in the UC treatment. Indeed, we find that outcome parameters of principals that voluntarily offer identical contracts to their agents in IC are not significantly different from outcome parameters for principals in UC. With an average wage of 44.45 tokens and an average actual effort level of 5.82 tokens (over all periods), these firms in the IC treatment exhibit only insignificantly lower numbers than in UC (where corresponding numbers are 47.15, respectively $6.57 ; p>0.4$ in the comparisons for both variables), while firms in the IC treatment that do not offer identical contracts have significantly lower average wages (32.60) and efforts (4.65) than in UC ( $p<0.05$ in both cases). Consequently, IC-firms that offer identical contracts achieve a similar level of earnings as firms in UC. In other words, the market in the IC treatment would have fared better with a higher level of within-firm uniformity of contracts, which has been exogenously imposed in the UC treatment. Hence, forcing firms to offer uniform contracts can be beneficial in certain situations. It is

\footnotetext{
${ }^{19}$ It is not surprising, however, that the quantitative level of reciprocity tends to be a bit lower in our experiment. This is due to the fact that each principal can employ up to three agents and, thus, can earn three times the amount of principals in the usual one-on-one setting. As a consequence, the level of reciprocity of individual agents tends to be lower but the reduction is much smaller than necessary if it was to equalize payoffs for principals and agents (see also Maximiano et al., 2007).
} 
noteworthy that our result for the IC treatment is not a consequence of social comparison within a given period. Remember that we did only provide details on contracts of co-agents within the same firm after everybody had exerted effort. Rather, it seems that it is an effect based on a joint underlying characteristic of some principals: Principals who are more likely to offer the same wages to their workers voluntarily are also more likely to offer higher wages and therefore earn more than other principals. The joint underlying characteristic that drives both action tendencies could be inequity aversion, but it could also be strategic intelligence.

\section{Discussing the determinants of the fair uniform-wage hypothesis}

We have found that uniform wages - regardless of whether they are chosen voluntarily (in the IC treatment) or whether they are exogenously imposed (in the UC treatment) - lead to significantly higher levels of voluntary effort provision and, consequently, to significantly higher levels of overall efficiency. This supports the fair uniform-wage hypothesis. However, it is important to emphasize that this main result is not driven by workers being more reciprocal as such for a given wage level (see Table 3 for convincing evidence). Rather, the average wage level is significantly higher with uniform wages than with differentiated wages.

The efficiency premium of uniform wages over differentiated wages builds up over time, and it is persistent over time, once it has built up. It does not exist in the first period, but starts to become significant from the second period on. Table 4 gives a detailed impression of the emergence of the difference between the IC treatment and the UC treatment by comparing averages of relevant variables in the first period and in the second period of each treatment. ${ }^{20}$ While there is no difference between the treatments in the first period, the following variables become significantly different already in the second period: market volume, i.e. the sum of all rents, wages, efforts, desired efforts and the profits of agents.

Insert Table 4 around here

\footnotetext{
${ }^{20}$ Because both, two sided t-tests and Mann-Whitney-U-tests produced qualitatively the same results, we report only the former.
} 
Obviously, the negative overall effect of differentiated wages in IC has to do with wage setting in connection with reputation in period 2 and later. In the IC treatment, principals can (implicitly) reward single agents by offering them an at least as favorable contract in period $t+1$ as in period $t$ if they complied with the desired effort level and principals can punish shirkers by decreasing the wage in the contract offer in period $t+1$ or by not re-employing them at all. Through the channel of private offers it is always possible to avoid hiring a shirker in period $t+1$. Public offers are much less profitable for agents than private offers ${ }^{21}$, because principals take into account that shirkers are more likely to accept public offers (they hardly receive any of the more profitable private offers). Hence, it is easy to reward reciprocal behavior through the use of private offers and to insure oneself as a principal against exploitation by not offering trust contracts publicly over the market in the IC treatment.

In the UC treatment, principals also have the opportunity not to re-employ shirking agents, but if they want to reward their compliant agents they have to make equally profitable contract offers in period $t+1$ to random other agents through private or public offers (facing the risk of re-employing or employing a shirker), because the threat of keeping the post vacant is not credible, given the forgone surplus. As a consequence, contract offers have to be much bolder in UC than in IC, leading to a significantly higher overall efficiency in UC. However, a priori it was completely unclear whether principals in the UC treatment would rather prefer to keep posts vacant or whether they would prefer to take the "risk" of making generous offers to new agents. It would have been conceivable that principals do not employ the maximum of three agents in the UC treatment and that, therefore, market efficiency goes down as a consequence of higher unemployment. Our results show, however, exactly the opposite.

Table 5 provides more evidence on the implicit asymmetry in reward and punishment between IC and UC. It shows that with private offers, the UC treatment starts out with even lower levels of wages than the IC treatment, although the difference is not significant on the session level with five independent observations. ${ }^{22}$ The important change occurs in the second period. While the average wage in accepted private offers stays practically the same in the IC treatment, we see a surge of wages in accepted private offers

\footnotetext{
${ }^{21}$ In IC the average wage in a public offer is 19.12 , but it is 40.91 in private offers $(p<0.01)$. In UC, the corresponding figures are 31.44, respectively $48.88(p<0.01)$.

${ }^{22}$ Again, a two sided t-test and a Mann-Whitney-U-test produced qualitatively the same results.
} 
from 39 to 52 in the UC treatment. Consistently, this is the region of wage offers that turned out to be profit maximizing for principals ex post. For the public offers on the market, a similar effect is observed. Here the level of wages in the UC treatment is already slightly higher than in the IC treatment in the first period, but not significantly so. While the average wage in accepted public offers falls in the IC treatment from period 1 to period 2 , indicating that principals get more reluctant to offer trust contracts to unknown agents, it increases substantially for the UC treatment, so that the difference between the two treatments in the second period becomes significant. Consequently, we observe a smaller difference between wages in accepted private offers and public offers in period 2 in the UC treatment (18.06 tokens) than in the IC treatment (23.53 tokens). ${ }^{23}$

\section{Insert Table 5 around here}

As a next step it is interesting to look how principals react to agents who show different degrees of reciprocity. For the sake of succinctness, we confine ourselves again to the transition from period 1 to period 2 . We compare the development of wages from period $1(w(t-1))$ to period $2(w(t))$ for three types of agents: (i) the one with the lowest effort level within the firm (min), (ii) the one with the medium effort level (med), and (iii) the one with the highest effort level $(\max )$ in period $t$ - 1 . In the IC treatment we see a very strong differentiation in wages contingent on efforts in the previous period. Whereas the average wage of those agents who provided the highest effort within their firm in period 1 increases from 35.67 tokens in period 1 to 59.17 tokens in period 2, the wages of the agents with the median and the minimum effort level within the firm in period 1 rise only by 1.40 and 0.15 tokens, respectively. In the UC treatment, where principals can only decide not to re-employ a specific agent but have to offer the same contract to new agents as to reciprocal ones, we do not observe such a differentiation. The wage difference between the first and the second period contingent on effort levels in the first period is very similar and does not depend systematically on whether one has provided the highest effort within the firm in period $1(w(t)-w(t-1)=8.47)$, the median effort $(w(t)-w(t-1)=10.44)$ or the minimum effort $(w(t)-w(t-1)=6.41)$.

\footnotetext{
${ }^{23}$ Our conclusions are confirmed when we use individual data instead of session averages. Note also that there is not much difference between actually accepted average wages and the average of all offered wages both publicly and privately (see bottom of Table 4). The same holds true for the first offer on the market in a specific period and the first accepted contract offer in that period. Hence, our conclusions go also through for posted offers and not only for accepted offers.
} 
Table 6 disentangles the result for agents that are employed by the same principal in the two periods and agents who are employed by different principals. Although the number of observations becomes rather small for certain categories, the overall picture is quite clear. Obviously, there is not much difference between the two treatments for re-employed agents, but there is a very stark difference similar to the one described above for the aggregated data for agents who are employed by another principal in period 2 .

\section{Insert Table 6 around here}

Recall that uniform wages within a firm are rare in the IC treatment. Compared to the behavioral social optimum, principals seem to over-differentiate wages or they seem to overuse the implicit sanctioning mechanisms (see also, for instance, Nikiforakis, 2008; Abbink et al., 2010), or they trust newly employed agents too little (see also, Bolton et al., 2004). However, their behavior is not necessarily irrational. Table 2 shows that principals earn more, on average, in UC (and at a lower standard deviation of income) than in IC, but not significantly so. In contrast to principals, agents clearly gain from uniform contracts. More precisely, most of the efficiency premium accrues to agents, which is not surprising, given their implicit bargaining power in a situation in which only a minimal effort level is contractible.

The main question of this section has been whether implementing a mandatory uniform wage within a firm for identical agents can be efficiency-enhancing? We can conclude with an affirmative answer now: Although such an institution impedes the principals' sanctioning toolbox, it leads to a clear increase in market efficiency. Hence, the results in this paper can be viewed as evidence that contractual limitations in markets with incomplete contracts can be beneficial.

\section{Conclusion}

This paper has been motivated by testing a forgotten part of Akerlof's (1982) seminal gift exchange hypothesis. What we have called the fair uniform-wage hypothesis is based on the second, often neglected aspect of gift exchange proposed by Akerlof (1982), and it is the sister of the well-known fair wage-effort hypothesis. The uniform-wage hypothesis 
stipulates that identical agents that are employed for the same wage level will exert more effort, resulting in more rent extraction, than agents that receive different wages.

Our results based on two experimental treatments - an individualized contracts treatment with no contractual limitations and a uniform contracts treatment with exogenously imposed uniformity of contracts within a firm - indicate that principals rarely offer identical contracts to a priori identical agents if they are allowed to differentiate individually, and that the number of uniform contracts within firms does not increase when principals get more experienced. The introduction of our (rather weak) institution of uniform (standardized) contracts within firms has a significant and economically relevant effect on market parameters. It increases average wages, average effort levels and, therefore, market efficiency and earnings considerably.

Hence, we empirically corroborate the importance of the fair uniform-wage hypothesis for efficiency levels on labor markets. Akerlof's (1982) theory was based on the insight that the bilateral gift exchange between a principal and an agent needs to be complemented by a social comparison among agents in a setting with multiple agents. We have shown that the total efficiency rent from gift exchange is, in fact, the result of a combination of the individual fair wage-effort relationship - which lets efforts respond positively to wages - and the fair uniform-wage relationship - which increases wages, and as a consequence efforts and market efficiency. Agents do not become more reciprocal with uniform contracts for a given wage level, however. The efficiency-enhancing effect is the consequence of eliminating a tendency of principals to over-differentiate contracts within their firm and to overuse implicit sanctioning of shirkers - if they are allowed to compared to the empirically optimal level. Note that there is also a higher re-employment rate in the uniform contracts treatment than in the individualized contracts treatment. In other words, the institution of exogenously implemented uniform contracts within a firm makes principals more forgiving, which in turn is beneficial for the achieved level of efficiency. It might "teach" agents the virtue of reciprocity in situations with incomplete contracts more quickly, and it reduces the impact of unemployment as a disciplining device (Brown et al., 2012), with positive effects on the market.

Implementing the institution of non-discrimination based on history becomes socially optimal, even if such an institution does not seem to be essential for the functioning of incomplete contract markets in the first place. Principals in our experiment obviously use the instrument of differentiation too frequently (in the individual contracts 
treatment). How does this result relate to labor markets in the field? Real-world applications for our findings have to exhibit two important features: (i) repeated interaction with reputation building, and (ii) incomplete contracts. Several industries, especially in the service sector, fulfill these characteristics to a large extent. For instance, in the tourism industry, workers are often employed only for one season and, depending on their performance, re-employed in the subsequent season. Although some features of their work can be contracted upon, there are, without doubt, important characteristics like friendliness to customers that are very difficult to write down in an enforceable contract. ${ }^{24}$

Are there other behavioral regularities that are able to explain the behavioral pattern that we observe in our experiment? If one assumes that agents are averse against being the sucker in their group, they might feel more secure in the uniform contract treatment because they know that everybody in their potential reference group receives the same wage, and therefore provide higher levels of effort. The effect we observe is, however, not driven by more reciprocal agents but by higher wages offered through principals. Furthermore, the let-down aversion explanation would imply a treatment effect right from the first period on, or at least a conversion of the outcomes in our two treatments over time. The latter would also be expected for any kind of non-equilibrium or learning theories as well as from different forms of inequity aversion models. If principals experiment in the beginning or simply make mistakes in their offers, we would anticipate a fading treatment effect over time, but the effect is persistent over time.

In general, the discussion on the use of (implicit) sanctions and their efficiency implications is far from conclusive. (Implicit) reward seems to work better in our labor market case than (implicit) punishment. In other words, more restricted sanctioning (in the uniform contract treatment) seems to work better from an efficiency perspective than less restricted sanctioning (in the individualized contract treatment). Whether this is a consequence of our setup or a more general conclusion, is worthwhile investigating in the future because existing evidence, mostly from social dilemmas, does not allow for a clear conclusion. ${ }^{25}$ In any case, we are - as far as we know - the first to address the issue of

\footnotetext{
${ }^{24}$ If one drops the labor market analogy and looks at product or service markets with non-enforceable quality, further applications become apparent, such as, for instance, whether it is beneficial to have a uniform price for medical services or whether non-uniform (individual) prices may ultimately lead to the provision of higher quality in the medical system.

${ }^{25}$ Our results provide another piece of evidence for the over-use of (implicit) sanctioning mechanisms (see, for instance, Herrmann et al., 2008). On the effects of restricted sanctioning in a public goods game, see Kroll et al. (2007).
} 
overuse of implicit sanctions and its adverse effects on efficiency in a labor market context. Another avenue for further research is to consider a bargaining process between principals and agents when setting wages, and whether bargaining will have an effect on how uniform wages affect wages, efforts, and market efficiency.

In sum, our results show that limiting contractual freedom can have positive effects on market efficiency and thus on welfare. With a growing number of workers within a firm working alongside each other with different contractual specifications (e.g., temporary workers and workers with a permanent contract), this is an essential insight for real-world labor markets. There is a social component to gift exchange (as hypothesized by Akerlof, 1982) in the sense that differentiation among agents in the same firm leads to an inferior result than equal treatment. However, the effect cannot be only a consequence of social comparison among agents; if it were, the treatment effect should become smaller over time, because agents learn also in the individualized treatment whether they have been treated equally by the principal or not at the end of each period. Our results imply that the virtue of an equal wage requirement within a firm is that it restricts the (over-)use of differentiation in wage and/or implicit sanctions based on the history of conduct of agents by principals. The requirement does not increase unemployment, generated by principals that keep posts deliberately vacant. Because unemployment levels stay the same, a uniform wage requirement is an effective tool in increasing overall market efficiency on labor markets. 


\section{References}

Abbink, Klaus, Jordi Brandts, Benedikt Herrmann, and Henrik Orzen (2010): Inter-group conflict and intra-group punishment in an experimental contest game. American Economic Review, 100, pp. 420-447.

Abeler, Johannes, Steffen Altmann, Sebastian Kube, and Matthias Wibral (2010): Gift exchange and workers' fairness concerns: when equality is unfair. Journal of the European Economic Association 8, pp. 1299-1324.

Akerlof, George A. (1982): Labor contracts as partial gift exchange. Quarterly Journal of Economics, 97, pp. 543-569.

Akerlof, Geoge A. and Janet L. Yellen (1988): Fairness and unemployment. American Economic Review, 78, pp. 44-49.

Akerlof, George A. and Janet L. Yellen (1990): The fair-wage effort hypothesis and unemployment, Quarterly Journal of Economics, 105, pp. 255-284.

Alewell, Dorothea, Colette Friedrich, Werner Güth, and Wiebke Kuklys (2007): Fair wages and multiple fairness standards - A lab study of co-employment of hired and rented hands. Schmalenbach Business Review, 59, pp. 2-28.

Bellemare, Charles and Bruce Shearer (2009): Gift giving and worker productivity: evidence from a firm-level experiment. Games and Economic Behavior, 67, pp. 233244.

Bewley, Truman F. (1999): Why wages don't fall during a recession. Harvard University Press, Cambridge/Mass.

Bolton, Gary and Axel Ockenfels (2000): ERC: A theory of equity, reciprocity, and competition. American Economic Review, 90, pp. 166-193.

Bolton, Gary, Elena Katok, and Axel Ockenfels (2004): How effective are electronic reputation mechanisms? An experimental investigation. Management Science, 50, pp. 1587-1602.

Brandts, Jordi and Gary Charness (2004): Do labor market conditions affect gift exchange? Some experimental evidence. Economic Journal, 114, pp. 684-708.

Brown, Martin, Armin Falk, and Ernst Fehr (2004): Relational contracts and the nature of market interactions. Econometrica, 72, pp. 747-780.

Brown, Martin, Armin Falk, and Ernst Fehr (2012): Competition and relational contracts: The role of unemployment as a disciplinary device. Journal of the European Economic Association, forthcoming. 
Cabrales, Antonio and Gary Charness (2011): Optimal contracts with team production and hidden information: An experiment. Journal of Economic Behavior and Organization, 77, pp. 163-176.

Card, David, Thomas Lemieux, and Craig Riddell (2004): Unions and wage inequality. Journal of Labor Research, 25, pp. 519-559.

Charness, Gary (2000): Responsibility and effort in an experimental labor market. Journal of Economic Behavior and Organization, 42, pp. 375-384.

Charness, Gary (2004): Attribution and reciprocity in an experimental labor market. Journal of Labor Economics, 22, pp. 665-688.

Charness, Gary and Peter J. Kuhn (2007): Pay inequality, pay secrecy, and effort: theory and evidence. Journal of Labor Economics, 25, pp. 693-724.

Charness, Gary and Peter J. Kuhn (2010): Lab labor: what can labor economists learn from the lab? NBER Discussion Paper No. 15913.

Charness, Gary and Matthew Rabin (2002): Understanding social preferences with simple tests. Quarterly Journal of Economics, 117, pp. 817-869.

Clark, Andrew, Paul Frijters, and Michael Shields (2008): Relative income, happiness, and utility: An explanation for the Easterlin paradox and other puzzles. Journal of Economic Literature, 46, pp. 95-144.

Clark, Andrew, Nicolai Kristensen, and Niels Westergård-Nielsen (2009): Job satisfaction and co-worker wages: Status or signal? Economic Journal, 119, pp. 430-447.

Cooper, David and John Kagel (forthcoming): Other regarding preferences: a selective survey of experimental results. In Kagel, J., and A. Roth: Handbook of experimental economics, vol. 2.

Falk, Armin and Urs Fischbacher (2006): A theory of reciprocity. Games and Economic Behavior, 54, 293-315.

Falk, Armin and Andrea Ichino (2006): Clean evidence on peer effects. Journal of Labor Economics, 24, pp. 39-57.

Falk, Armin and Michael Kosfeld (2006): The hidden costs of control. American Economic Review, 96, 1611-1630.

Fehr, Ernst and Armin Falk (1999): Wage rigidities in a competitive incomplete contract market. Journal of Political Economy, 107, pp. 106-134.

Fehr, Ernst and Klaus M. Schmidt (1999): A theory of fairness, competition, and cooperation. Quarterly Journal of Economics, 114, pp. 817-868. 
Fehr, Ernst, Georg Kirchsteiger, and Arno Riedl (1993): Does fairness prevent market clearing? An experimental investigation. Quarterly Journal of Economics, 108, pp. 437-460.

Fehr, Ernst, Georg Kirchsteiger, and Arno Riedl (1998a): Gift exchange and reciprocity in competitive experimental markets. European Economic Review, 42, pp. 1-34.

Fehr, Ernst, Erich Kirchler, Andreas Weichbold, and Simon Gächter (1998b): When social norms overpower competition: Gift exchange in experimental labor markets. Journal of Labor Economics, 16, pp. 324-351.

Fehr, Ernst, Armin Falk, and Christian Zehnder (2006): The behavioral effects of minimum wage laws. Quarterly Journal of Economics, 121, pp. 1347-1381.

Fehr, Ernst, Alexander Klein, and Klaus M. Schmidt (2007): Fairness and contract design. Econometrica, 75, pp. 121-154.

Fischbacher, Urs (2007): Z-Tree: Zurich toolbox for ready-made economics experiments. Experimental Economics, 10, pp. 171-178.

Freeman, Richard B. (1982): Union wage practices and wage dispersion within establishments. Industrial and Labor Relations Review, 36, pp. 3-21.

Fudenberg, Drew and Eric Maskin (1986): The folk theorem for repeated games with discounting and incomplete information. Econometrica, 54, pp. 533-554.

Gächter, Simon, Daniele Nosenzo, and Martin Sefton (2010): The impact of social comparisons on reciprocity, CeDEx Discussion Paper, University of Nottingham.

Galizzi, Monica and Kevin Lang (1998): Relative wages, wage growth and quit behavior. Journal of Labor Economics, 16, pp. 367-391.

Gintis, Herbert (1976): The nature of labor exchange and the theory of capitalist production. Review of Radical Political Economics, 8, pp. 36-54.

Gneezy, Uri and John A. List (2006): Putting behavioral economics to work: Testing for gift exchange in labor markets using field experiments. Econometrica, 74, pp. 13651384

Güth, Werner, Martin G. Kocher, and Vera Popava (2010): Co-employment of permanently and temporarily employed agents. Discussion Paper, Max-Planck Institute of Economics, Jena.

Hannan, R. Lynn, John H. Kagel, and Donald V. Moser (2002): Partial gift exchange in experimental labor markets: Impact of subject population differences, productivity 
differences and effort requests on behavior. Journal of Labor Economics, 20, pp. 923-951.

Henning-Schmidt, Heike, Bettina Rockenbach, and Abdolkarim Sadrieh (2010): In search of workers' real effort reciprocity - a field and a laboratory experiment. Journal of the European Economic Association, 8, pp. 817-837.

Herrmann, Benedikt, Christian Thöni, and Simon Gächter (2008): Antisocial punishment across societies. Science, 319, 1362-1366.

Irlenbusch, Bernd and Dirk Sliwka (2005): Incentives, decision frames and crowding out: an experimental investigation. IZA Discussion Paper No. 1758.

Kahn, Lawrence (2012): Labor market policy: A comparative view on the costs and benefits of labor market flexibility. Journal of Policy Analysis and Management, 31, pp. 94-110.

Kirchsteiger, Georg, Muriel Niederle and Jan Potters (2005): Endogenizing market institutions: An experimental approach. European Economic Review, 49, pp. 18271853.

Kocher, Martin G. and Sebastian Strasser (2012): The fair employment hypothesis: Reciprocity in unstable environments. Mimeo.

Kreps, David M., Paul Milgrom, John Roberts, and Robert Wilson (1982): Rational cooperation in the finitely repeated prisoners' dilemma. Journal of Economic Theory, 27, pp. 245-252.

Kroll, Stephan, Todd L. Cherry and Jason F. Shogren (2007): Voting, punishment, and public goods. Economic Inquiry, 45, pp. 557-570.

Kube, Sebastian, Clemens Puppe, and Michel Maréchal. (2012): The currency of reciprocity - gift-exchange in the workplace. American Economic Review, forthcoming.

Levine, David K. (1998): Modeling altruism and spitefulness in experiments. Review of Economic Dynamics, 1, pp. 593-622.

Maximiano, Sandra, Randolph Sloof, and Joep Sonnemans (2007): Gift exchange in a multi-worker firm. Economic Journal, 117, pp. 1025-1050.

Neumark, David and Andrew Postlewaite (1998): Relative income concerns and the rise in married women's employment. Journal of Public Economics, 70, pp. 157-183.

Nikiforakis, N.ikos (2008): Punishment and counter-punishment in public-good games: Can we really govern ourselves? Journal of Public Economics, 92, pp. 91-112. 
Owens, Marc F. and John H. Kagel (2010): Minimum wage restrictions and employee effort in incomplete labor markets: an experimental investigation. Journal of Economic Behavior and Organization, 73, pp. 317-326.

Rabin, Matthew (1993): Incorporating fairness into game theory and economics, American Economic Review, 83, pp. 1281-1302. 


\section{Tables and figures}

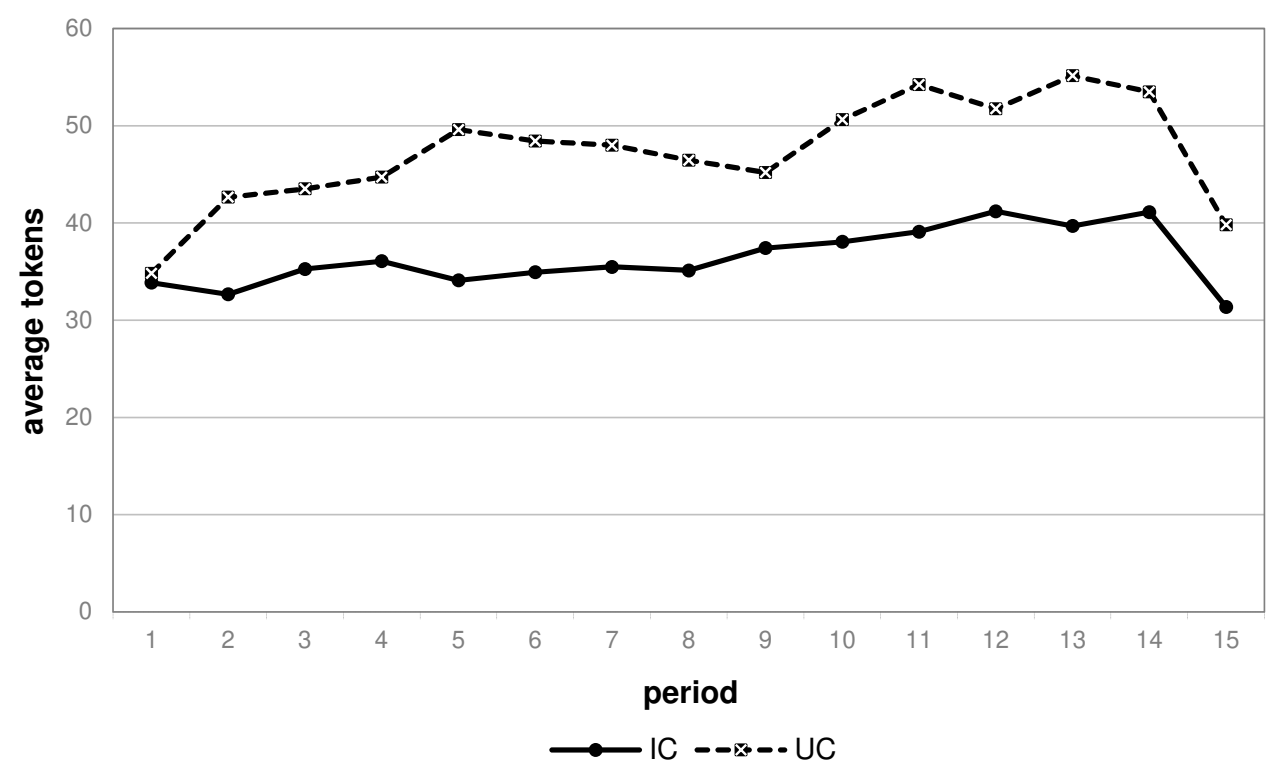

Figure 1. Average wages

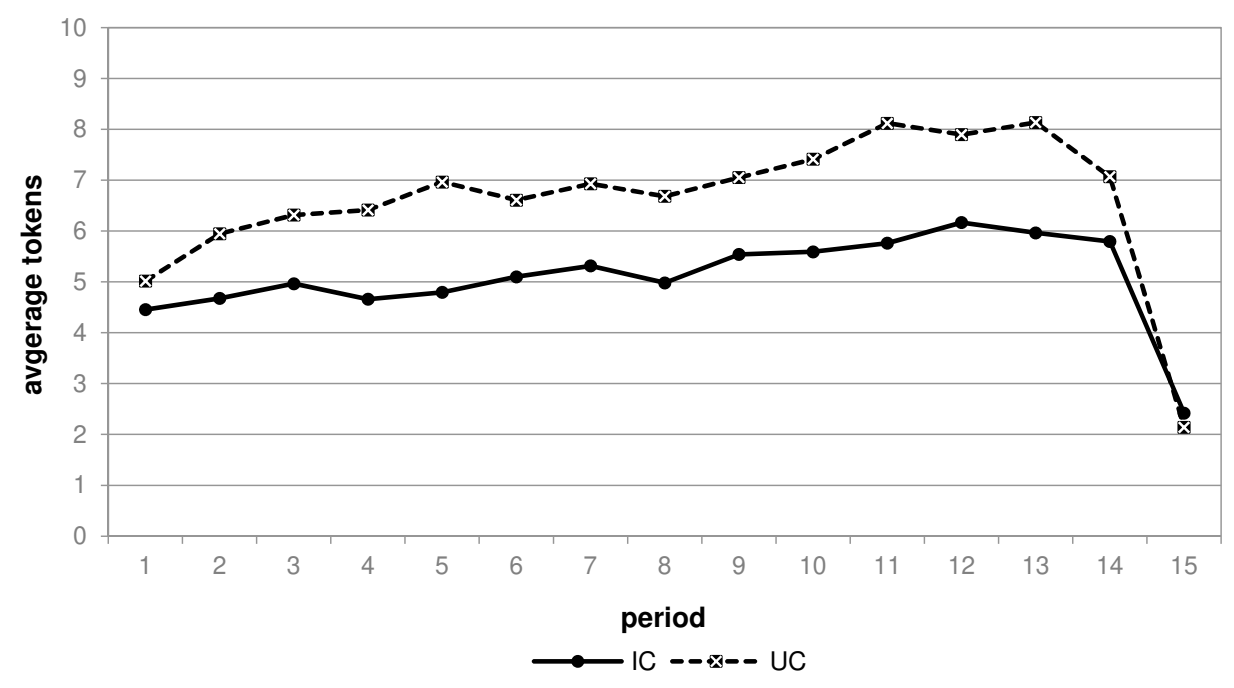

Figure 2. Average efforts 


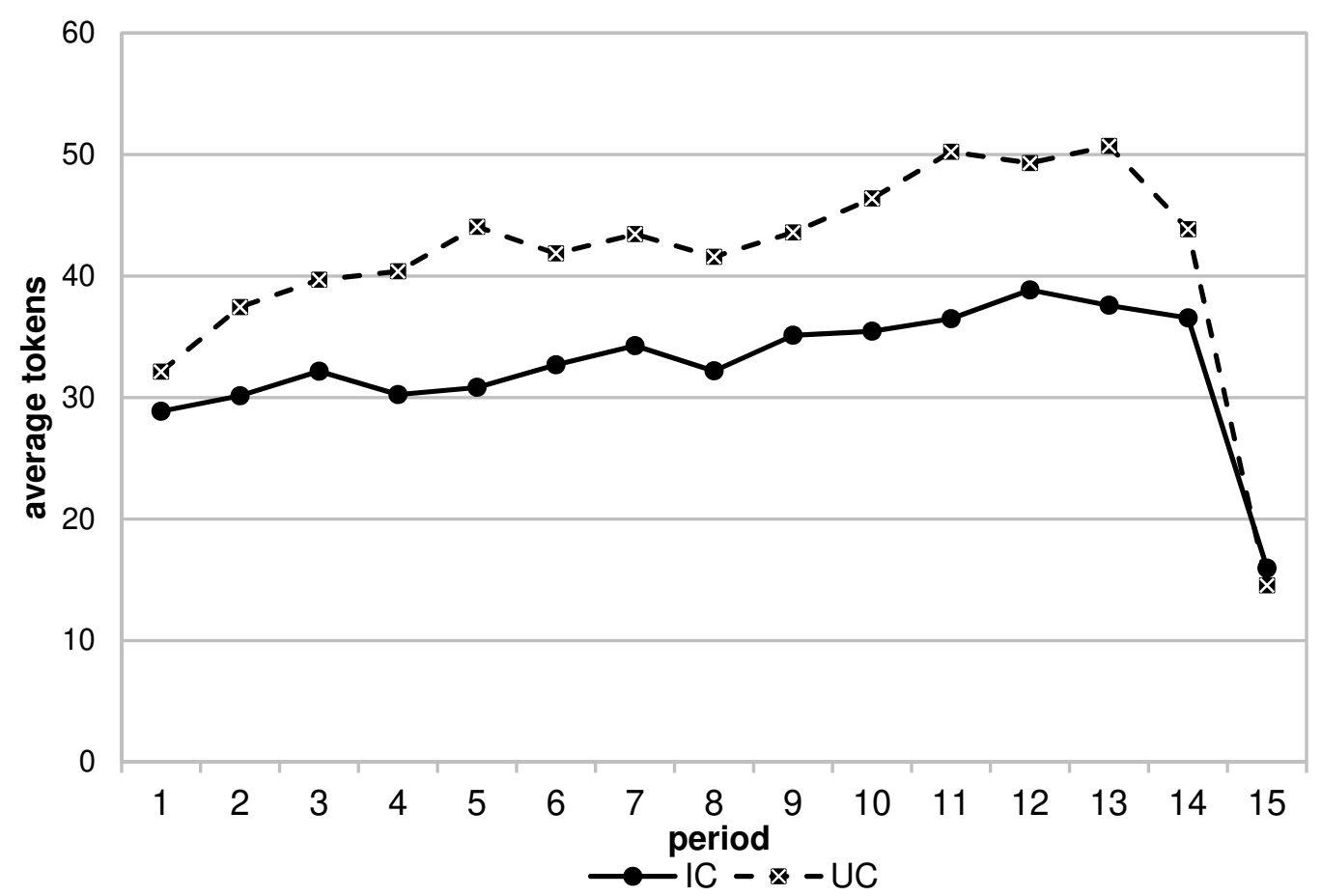

Figure 3. Average payoffs (period means) 


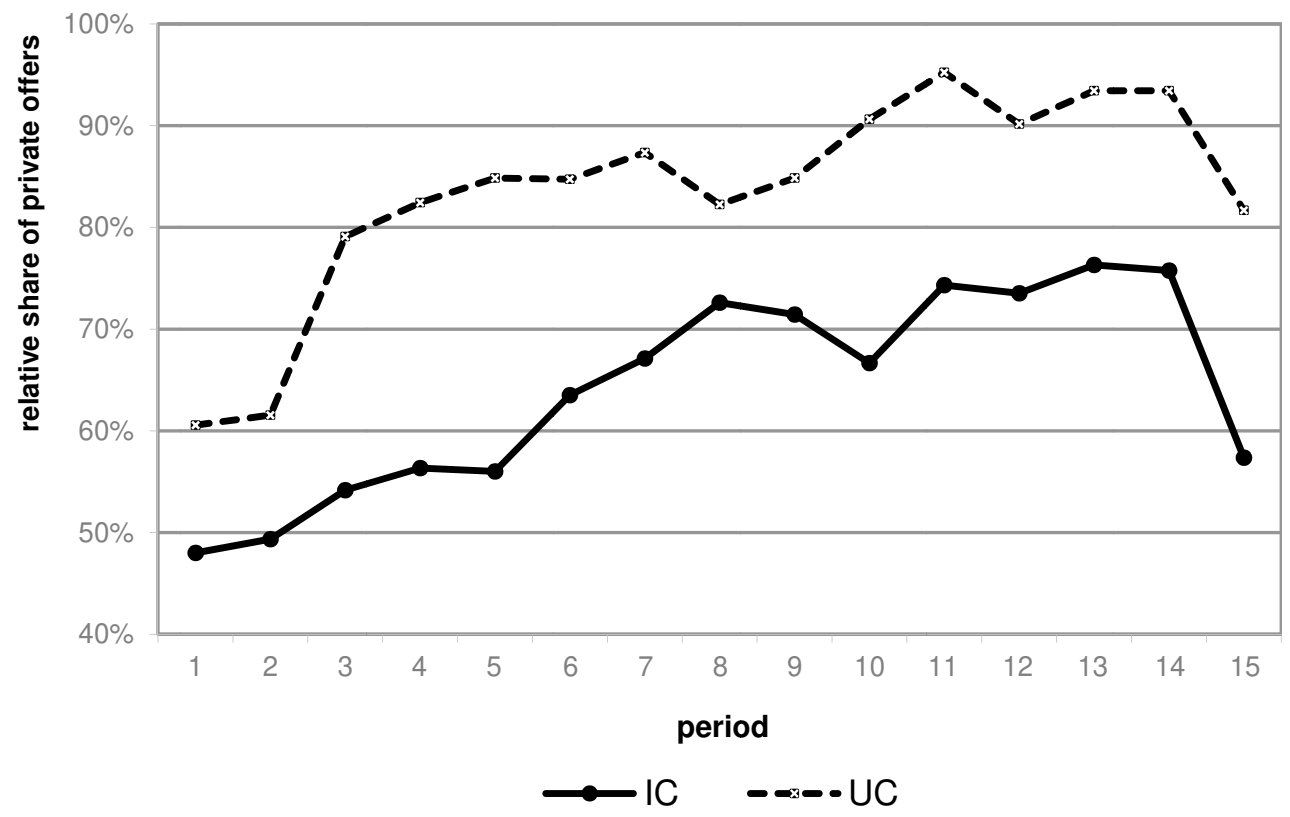

Figure 4. Shares of private offers

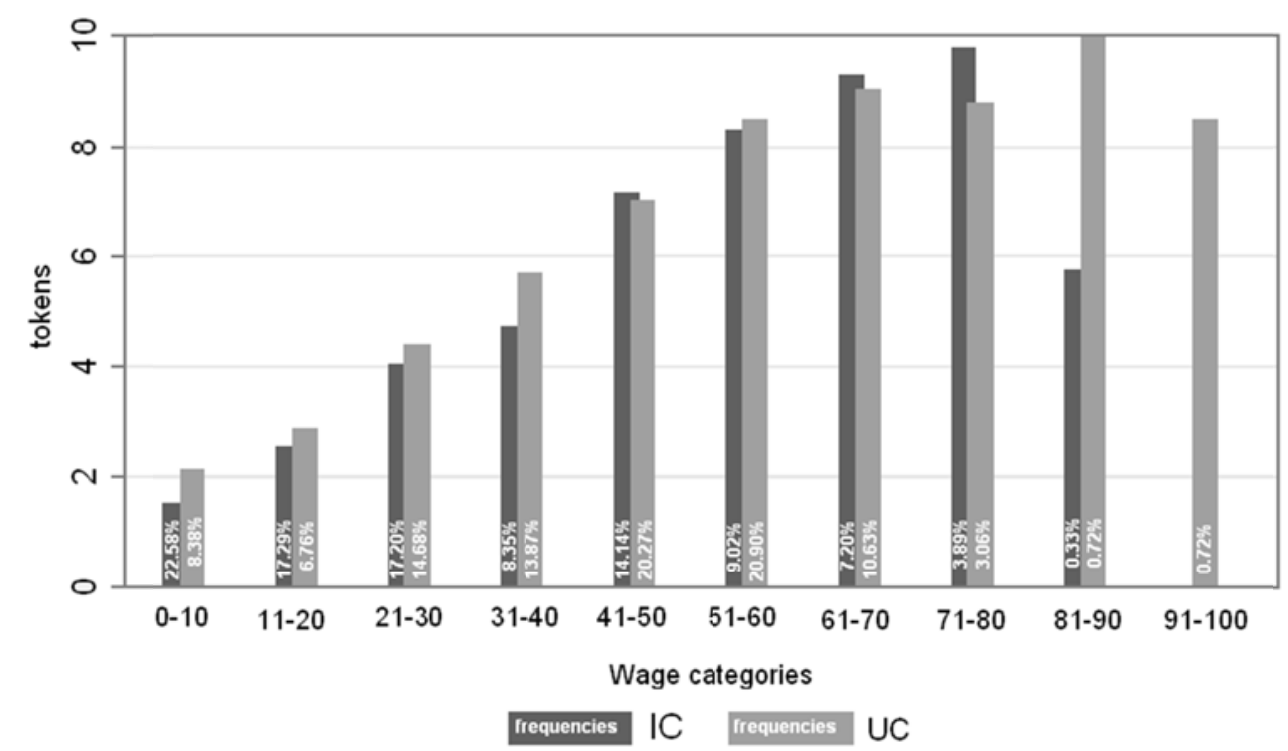

Figure 5. Mean efforts conditional on wages

Table 1. Cost of effort

\begin{tabular}{ccccccccccc}
\hline$e$ & 1 & 2 & 3 & 4 & 5 & 6 & 7 & 8 & 9 & 10 \\
$c(e)$ & 0 & 1 & 2 & 4 & 6 & 8 & 10 & 12 & 15 & 18 \\
\hline
\end{tabular}


Table 2. Overview of descriptive results

\begin{tabular}{lccc}
\hline \multicolumn{1}{c}{ Variables } & IC & UC & $\begin{array}{c}\text { p (Mann- } \\
\text { Whitney-U; } \text { two- } \\
\text { sided })\end{array}$ \\
\hline Market Volume* & $\mathbf{5 2 7 . 6 5 ( 1 2 8 . 8 1 )}$ & $\mathbf{6 5 2 . 6 1}(94.32)$ & 0.076 \\
Share Principal & $0.27(0.07)$ & $0.28(0.06)$ & 0.465 \\
Wage & $\mathbf{3 6 . 3 5}(8.17)$ & $\mathbf{4 7 . 1 5}(4.25)$ & 0.047 \\
Effort & $\mathbf{5 . 0 9}(1.50)$ & $\mathbf{6 . 5 7}(0.80)$ & 0.047 \\
Desired Effort & $7.01(0.95)$ & $7.91(1.07)$ & 0.117 \\
Number of Contracts & $11.68(0.23)$ & $11.57(0.49)$ & 0.754 \\
Number of Offers & $14.64(2.05)$ & $13.47(1.18)$ & 0.602 \\
Share of Private Offers & $\mathbf{0 . 6 6}(0.16)$ & $\mathbf{0 . 8 3}(0.16)$ & 0.076 \\
Profit Principal per Contract & $14.58(6.91)$ & $18.54(5.36)$ & 0.347 \\
Profit Principal & $42.59(20.50)$ & $53.96(16.52)$ & 0.465 \\
Profit Agent & $\mathbf{2 9 . 1 3 ( 5 . 0 6 )}$ & $\mathbf{3 7 . 0 6}(3.36)$ & 0.028 \\
Average Tenure & $2.09(1.48)$ & $2.68(0.77)$ & 0.602 \\
\hline
\end{tabular}

Note: We display the overall means with standard deviations in parentheses. All observations are measured in experimental tokens and percent, respectively. Significance tests have been conducted using the mean values of each experimental session, thereby using five independent observations per treatment on each variable. Bold numbers indicate a (partly, weakly) significant difference between the two treatments.

*Market volume is calculated as the sum of all earnings on the market in one period. 
Table 3. Tobit estimations

\begin{tabular}{|c|c|c|c|c|}
\hline \multicolumn{5}{|c|}{ Dependent Variable: Effort (censored at 1 and 10) } \\
\hline Model & 1 & 2 & 3 & 4 \\
\hline Constant & $\begin{array}{c}-1.200 * * * \\
(3.84)\end{array}$ & $\begin{array}{c}-0.889 * * * \\
(2.83)\end{array}$ & $\begin{array}{c}1.444 * * * \\
(4.00)\end{array}$ & $\begin{array}{c}-1.082 * * * \\
(2.98)\end{array}$ \\
\hline Wage & $\begin{array}{c}0.162 * * * \\
(35.29)\end{array}$ & $\begin{array}{c}0.154 * * * \\
(32.62)\end{array}$ & $\begin{array}{c}0.167 * * * \\
(27.77)\end{array}$ & $\begin{array}{c}0.158 * * * \\
(25.64)\end{array}$ \\
\hline Period & $\begin{array}{c}0.210 * * * \\
(4.04)\end{array}$ & $\begin{array}{c}0.187 * * * \\
(3.62)\end{array}$ & $\begin{array}{c}0.220 * * * \\
(4.20)\end{array}$ & $\begin{array}{c}0.195 * * * \\
(3.75)\end{array}$ \\
\hline Period $^{2}$ & $\begin{array}{c}-0.022 * * * \\
(6.42)\end{array}$ & $\begin{array}{c}-0.025 * * * \\
(7.04)\end{array}$ & $\begin{array}{c}-0.023 * * * \\
(6.54)\end{array}$ & $\begin{array}{c}-0.025 * * * \\
(7.11)\end{array}$ \\
\hline Tenure & - & $\begin{array}{c}0.165^{* * * *} \\
(5.50)\end{array}$ & - & $\begin{array}{c}0.163 * * * \\
(5.44)\end{array}$ \\
\hline Private & $\begin{array}{c}1.654 * * * \\
(8.50)\end{array}$ & $\begin{array}{c}1.514 * * * \\
(7.78)\end{array}$ & $\begin{array}{c}1.621 * * * \\
(8.28)\end{array}$ & $\begin{array}{c}1.490 * * * \\
(7.61)\end{array}$ \\
\hline$U C$ Dummy & $\begin{array}{l}0.142 \\
(0.44)\end{array}$ & $\begin{array}{c}-0.973 * * * \\
(3.03)\end{array}$ & $\begin{array}{c}-0.945^{*} \\
(1.87)\end{array}$ & $\begin{array}{c}-0.982 * * \\
(1.96)\end{array}$ \\
\hline$U C^{*}$ Wage Dummy & - & - & $\begin{array}{c}-0.011 \\
(1.37) \\
\end{array}$ & $\begin{array}{c}-0.009 \\
(1.07) \\
\end{array}$ \\
\hline Observations & 1952 & 1952 & 1952 & 1952 \\
\hline Log likelihood & -3463.45 & -3462.88 & -3478.6 & -3477.66 \\
\hline
\end{tabular}

Absolute value of $\mathrm{z}$ statistics in parentheses.

* significant at $10 \%$; * significant at $5 \%$; *** significant at $1 \%$. 
Table 4. Mean values in periods 1 and 2 (and difference tests)

\begin{tabular}{|c|c|c|c|c|c|c|}
\hline Period means & $\begin{array}{c}\text { IC } \\
\text { Per } 1\end{array}$ & $\begin{array}{c}\text { UC } \\
\text { Per } 1\end{array}$ & $\begin{array}{c}\text { Two- } \\
\text { sided } t- \\
\text { test } p \\
\text { Per } 1 \\
\end{array}$ & $\begin{array}{c}\text { IC } \\
\text { Per } 2\end{array}$ & $\begin{array}{c}\text { UC } \\
\text { Per } 2\end{array}$ & $\begin{array}{c}\text { Two-sided } \\
\text { t-test } p \\
\text { Per2 }\end{array}$ \\
\hline Market Volume & 444.400 & 510.600 & 0.401 & 455.200 & 577.400 & 0.015 \\
\hline Share Principal & 0.265 & 0.340 & 0.245 & 0.340 & 0.329 & 0.863 \\
\hline Wage & 33.900 & 34.582 & 0.877 & 32.838 & 42.614 & 0.011 \\
\hline Effort & 4.465 & 4.977 & 0.506 & 4.730 & 5.938 & 0.044 \\
\hline Desired Effort & 6.767 & 6.759 & 0.991 & 6.612 & 7.686 & 0.022 \\
\hline Number of Contracts & 11.400 & 11.800 & 0.397 & 11.200 & 11.400 & 0.667 \\
\hline Number of Offers & 15.000 & 14.200 & 0.509 & 15.400 & 13.000 & 0.082 \\
\hline Share of Private Offers & $47.49 \%$ & $60.52 \%$ & 0.130 & $50.61 \%$ & $60.56 \%$ & 0.527 \\
\hline $\begin{array}{l}\text { Profit Principal } \\
\text { per Contract }\end{array}$ & 10.745 & 15.191 & 0.284 & 14.459 & 16.765 & 0.564 \\
\hline Profit Principal & 122.000 & 181.200 & 0.232 & 158.200 & 191.800 & 0.431 \\
\hline Profit Agent & 28.310 & 27.759 & 0.857 & 26.600 & 33.823 & 0.017 \\
\hline Average Tenure & 0.000 & 0.000 & no test & 0.388 & 0.355 & 0.805 \\
\hline Offered wages & 34.460 & 31.183 & 0.646 & 31.248 & 42.583 & 0.019 \\
\hline Publicly offered wages & 25.193 & 29.557 & 0.420 & 22.952 & 34.054 & 0.020 \\
\hline Privately offered wages & 43.218 & 35.140 & 0.298 & 38.825 & 50.945 & 0.137 \\
\hline
\end{tabular}


Table 5. Accepted private and public wage offers

\begin{tabular}{|c|c|c|c|c|c|}
\hline \multicolumn{3}{|c|}{ Treatment } & Mean & St. Dv. & Obs. \\
\hline \multirow{5}{*}{ 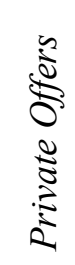 } & \multirow{3}{*}{$I C$} & Period 1 & 48.793 & 3.72 & 5 \\
\hline & & Period 2 & 47.190 & 2.57 & 5 \\
\hline & & Total & 44.242 & 3.94 & 5 \\
\hline & \multirow{3}{*}{$U C$} & Period 1 & 39.360 & 6.25 & 5 \\
\hline & & Period 2 & 52.114 & 5.19 & 5 \\
\hline & & Total & 50.089 & 1.48 & 5 \\
\hline \multirow{3}{*}{\multicolumn{2}{|c|}{$\begin{array}{c}t \text {-test } p: \\
\text { (two sided) }\end{array}$}} & \multirow{3}{*}{\multicolumn{2}{|c|}{$\begin{array}{l}\text { IC vs. UC: Per } 1 \\
\text { IC vs. UC: Per } 2 \\
\text { IC vs. UC: Total }\end{array}$}} & \multirow{3}{*}{\multicolumn{2}{|c|}{$\begin{array}{l}0.2310 \\
0.4193 \\
0.2022\end{array}$}} \\
\hline & & & & & \\
\hline & & & & & \\
\hline \multicolumn{3}{|c|}{ Treatment } & Mean & St. Dv. & Obs. \\
\hline \multirow{6}{*}{ 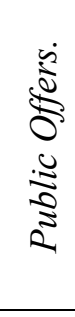 } & \multirow{3}{*}{$I C$} & Period 1 & 25.526 & 3.55 & 5 \\
\hline & & Period 2 & 23.656 & 1.53 & 5 \\
\hline & & Total & 19.038 & 4.69 & 5 \\
\hline & \multirow{3}{*}{$U C$. } & Period 1 & 29.557 & 4.89 & 5 \\
\hline & & Period 2 & 34.054 & 3.64 & 4 \\
\hline & & Total & 31.914 & 4.41 & 5 \\
\hline \multirow{3}{*}{\multicolumn{2}{|c|}{$\begin{array}{c}\text { t-test } p: \\
\text { (two sided) }\end{array}$}} & \multirow{3}{*}{\multicolumn{2}{|c|}{$\begin{array}{l}\text { IC vs. UC: Per } 1 \\
\text { IC vs. UC: Per } 2 \\
\text { IC vs. UC: Total }\end{array}$}} & \multicolumn{2}{|c|}{0.5232} \\
\hline & & & & \multirow{2}{*}{\multicolumn{2}{|c|}{$\begin{array}{l}0.0245 \\
00299\end{array}$}} \\
\hline & & & & & \\
\hline
\end{tabular}


Table 6 . Wage changes from period 1 to period 2

A) All employments in period 2

\begin{tabular}{llccc} 
& & \multicolumn{3}{c}{ Effort Rank in Period 1 } \\
\cline { 2 - 5 } min & $N$ & med & max \\
IC & $w(t-1)$ & 27.60 & 32.00 & 15 \\
& $w(t)$ & 27.27 & 32.50 & 49.73 \\
& $w(t)-w(t-1)$ & -0.33 & 0.50 & 11.27 \\
\hline \hline \multirow{4}{*}{$U C$} & $N$ & 17 & 9 & 17 \\
& $w(t-1)$ & 35.18 & 34.78 & 35.18 \\
& $w(t)$ & 41.59 & 45.22 & 43.65 \\
& $w(t)-w(t-1)$ & 6.41 & 10.44 & 8.47 \\
\hline
\end{tabular}

B) Same employer in period 2

Effort Rank in Period 1

\begin{tabular}{clccc} 
& & min & med & max \\
\cline { 2 - 5 }$I C$ & $N$ & 7 & 3 & 9 \\
& $w(t-1)$ & 30.57 & 33.33 & 47.11 \\
& $w(t)$ & 33.43 & 31.67 & 52.78 \\
& $w(t)-w(t-1)$ & 2.86 & -1.67 & 5.67 \\
\hline \hline \multirow{4}{*}{$U C$} & $N$ & 7 & 6 & 9 \\
& $w(t-1)$ & 46.14 & 43 & 44.78 \\
& $w(t)$ & 48.86 & 45.33 & 51.33 \\
& $w(t)-w(t-1)$ & 2.71 & 2.33 & 6.56 \\
\hline
\end{tabular}

C) Different employers in periods 1 and 2

Effort Rank in Period 1

\begin{tabular}{llccc} 
& & min & med & max \\
\cline { 2 - 5 }$I C$ & $N$ & 8 & 3 & 6 \\
\multirow{2}{*}{$w(t-1)$} & 25.00 & 30.67 & 23.67 \\
& $w(t)$ & 21.88 & 33.33 & 43.33 \\
& $w(t)-w(t-1)$ & -3.13 & 2.67 & 19.67 \\
\hline \hline \multirow{4}{*}{$U C$} & & min & med & $\max$ \\
\cline { 2 - 5 } & $N$ & 10 & 3 & 8 \\
& $w(t-1)$ & 27.50 & 18.33 & 24.38 \\
& $w(t)$ & 36.50 & 45.00 & 35.00 \\
& $w(t)-w(t-1)$ & 9.00 & 26.67 & 10.63 \\
\hline
\end{tabular}




\section{Appendix A: Instructions for the UC treatment (Originally in German; not for publication - will be provided on the authors' website)}

The aim of this experiment is to investigate economic decision making. During the experiment you and the other participants will be asked to make decisions. You will earn money in doing so. The amount of your payoff is determined by your own decision as well as by those made by the other participants according to the rules on the following pages.

\section{2 types of participants}

There are two types of participant: type A and type B. You will be randomly assigned to one of these roles. Your role (A or B) is displayed on the upper range of your screen throughout the experiment. Your role will stay the same (A or B) throughout the whole experiment.

\section{Earnings}

At the beginning of the experiment you will receive an initial endowment of 3 Euro. During the course of the experiment you can earn a further amount of money by gaining points. All points that you gain during the course of the experiment will be exchanged into Euro at the end of the experiment. The exchange rate will be:

$$
\begin{gathered}
1 \text { point }=0.03 \text { Euro }(3 \text { Eurocent }) \text {; } \\
\text { therefore } 1 \text { Euro }=33.33 \text { points }
\end{gathered}
$$

At the end of the experiment you will be paid the money that you earned during the experiment in addition to your endowment of 3 Euro, privately and in cash.

\section{Duration}

The experiment will take approx. 150 minutes. It is divided into 15 periods. In each period you have to make decisions, which you will enter on a computer screen.

\section{Documentation}

The last page of these instructions contains a documentation sheet. At the beginning of the experiment you have to fill in your identification number (displayed on the screen). In each round you will fill in certain information (see below) into the corresponding rows. Please hand this sheet in at the end of the experiment.

\section{Anonymity}

The identities of the participants you interacted with will not be revealed to you at any point in time. Neither during nor after the experiment will any of the other participants be informed about your role, or how much you have earned.

Please note that communication between participants is strictly prohibited during the experiment. In addition we would like to point out that you may only use the computer functions which are required for the experiment. Communication between participants and unnecessary tinkering with the computer will lead to immediate exclusion from the experiment.

\section{An Overview of the Experimental Procedures}

In each period of the experiment every Type A participant can conclude trades with three participants of type B. Type B earns a profit if he receives a transfer which exceeds his costs. Type A earns a profit if the transfer he sends is less than what the factor is worth to him. The costs that type B has to bear and the earnings of type A are determined by the factor chosen by type B.

The experiment lasts for 15 periods. In each period the procedures are as follows:

1. Each period starts with a trading phase which lasts 3 minutes. During this phase participants of type A can submit offers which can be accepted by participants of type B. A buyer has to specify three components when submitting an offer:

- which transfer he offers to send,

- which factor he desires,

- , which type B he wants to submit the offer to. 
Type A participants can submit two types of offers; private offers and public offers. Private offers are submitted to one type B only and can only be accepted by that particular participant. Public offers are submitted to all type B participants and can be accepted by any type B.

Type A participants can - in each period - submit as many offers as they like. Submitted offers can be accepted at any time during the trading phase. Each type B participant can at most conclude one trade in each period. Each type A participant can at most conclude three trades per period. As there are 16 type B and 4 type A participants, several type Bs will not trade in each period.

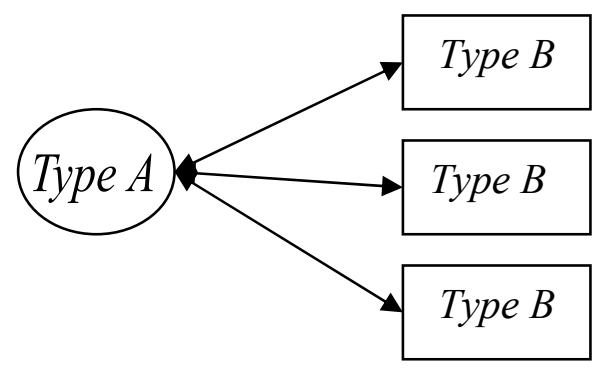

2. Following the trading phase each type $\mathrm{B}$ who has concluded a trade determines which factor he will send. Type B is not obliged to send the factor desired by the type A. Once every participant of type B has chosen a factor each participant's earnings in the current period are determined. After this the next period starts.

The points gained during all 15 periods will be summed up at the end of the experiment, exchanged into EURO and paid together with your endowment in cash.

As a reference to the real world, one can think of the experiment as a labor market: Type A is the employer offering job contracts, containing the wage (transfer) and the desired effort i.e., working hours etc. (factor). Each employer can hire 3 employees (see figure 1). After being employed (having accepted the offer) the workers decide whether to accomplish the desired effort or not.

\section{The Experimental Procedure in Detail}

There are 4 type A and 16 type B participants in the experiment. Your role will stay the same (A or B) throughout the whole experiment. Next, we provide a detailed description about your decision in each period.

\section{The trading phase}

\section{TYPE A}

Each period starts with a trading phase. During the trading phase each Type A can conclude a trade with up to three type B participants. In order to do so each type A can submit as many offers as he wishes.

In each trading phase participants of Type A see the following screen: 


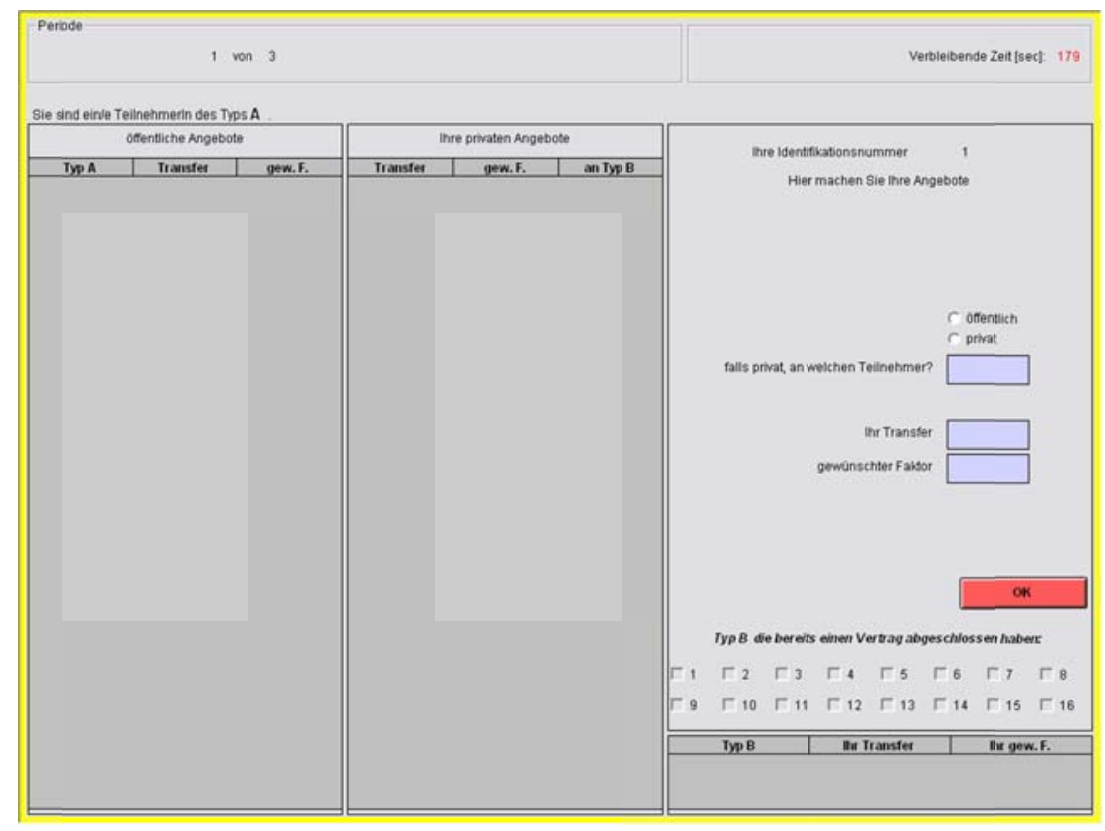

In the top left corner of the screen the current period of the experiment is displayed. In the top right corner of the screen the time remaining in this trading phase is displayed in seconds. Each period lasts 3 minutes (= 180 seconds). When this time is up the trading phase is over. Hereafter, no further offers can be submitted or accepted in this period.

Once the above screen is displayed the trading phase has started. Type A participants have the possibility to submit offers to the sellers. In order to do so you have to enter three specifications on the right hand side of the screen:

a) First the participants of type A have to specify whether to submit a public or a private offer:

\section{- Public offers}

Public offers will be communicated to all participants in the market. All type B participants see all public offers on their screens. A public offer can therefore be accepted by any type B participant. The type A participants will also see all public offers submitted by other type A participants.

To submit a public offer, click on the circle labeled "public", using the cursor.

\section{- Private offers}

A private offer is submitted to one particular type B participant only. Only this type B is informed about the offer and only this participant can accept the offer. No other type B or type A participant will be informed about that offer.

To submit a private offer, click on the circle labeled "private" using the cursor. The type B participant, the offer shall be submitted to, has to be specified in the box below. Each of the 16 type Bs has an identification number (type B 1, type B 2, ....., type B 16). Each type B keeps his identification number throughout the whole experiment. To submit an offer to a specific type $\mathrm{B}$ enter the number of that participant (e.g., "4" for type B 4).

b) After having specified to whom to submit an offer, the type A participants must determine which transfer is offered.

This is entered in the box labeled "Your transfer". The transfer offered is a number between 0 and 100:

\section{$\mathbf{0} \leq$ transfer offered $\leq \mathbf{1 0 0}$}

c) Finally type A participants have to specify which factor they desire. This is entered in the box labeled "Desired factor".

The desired factor is a number between 1 and 10 :

\section{$1 \leq$ desired factor $\leq 10$}

After having completely specified the offer, it is submitted by clicking the "OK" button. As long as the "OK" button has not been clicked the offer can be changed. When confirmed by the "OK" button the offer will be displayed to all type B participants it was submitted to.

The header "public offers" is located on the top of the left side column on the screen. All public offers in the current trading phase are displayed here. Your public offers as well as those of all other participants of type A will be displayed. More specifically, the ID of the participant who submitted the offer, which transfer was 
offered and the desired factor are displayed. All type A participants also have an identification number, which they keep throughout the whole experiment.

In the middle of the screen below the header "Your private offers" all your private offers submitted in the current trading phase are listed. The offered transfer, the desired factor and the ID of the participant to which each offer was submitted are displayed.

Each Type A can submit as many offers as she wishes public or private, no matter if they are of identical or differing content. Each offer can be accepted at any time during the trading phase.

In any given period each participant of type A can conclude at most three trades. Once an offer has been accepted, type A will be notified which type B accepted which of his offers. In the bottom right corner of the screen the identification number of the type B participant will be displayed as well as the offered transfer and desired factor. As type A participants can conclude only three trades in each period all other offers will be cancelled automatically after the third offer has been accepted, and this type A will not be able to submit any further offers during this period.

In any given period each participant of type B can conclude at most one trade. The type A participants will be continuously informed which type B participants have not yet accepted an offer. On the right bottom of the screen you will find 16 boxes, one for each of the 16 type B participants. Once a type B has accepted an offer an " $x$ " will appear in the box next to the participant's identification number. It is not possible to submit private offers to a participant of type B who has already concluded a trade.

\section{TYPE B}

In each trading phase participants of Type B see the following screen:

In the top left corner of the screen the current period of the experiment is displayed. In the top right corner of the screen the time remaining in this trading phase is displayed in seconds. Each period lasts 3 minutes (= 180 seconds). When this time is up the trading phase is over. Hereafter, no further offers can be submitted or accepted in this period.

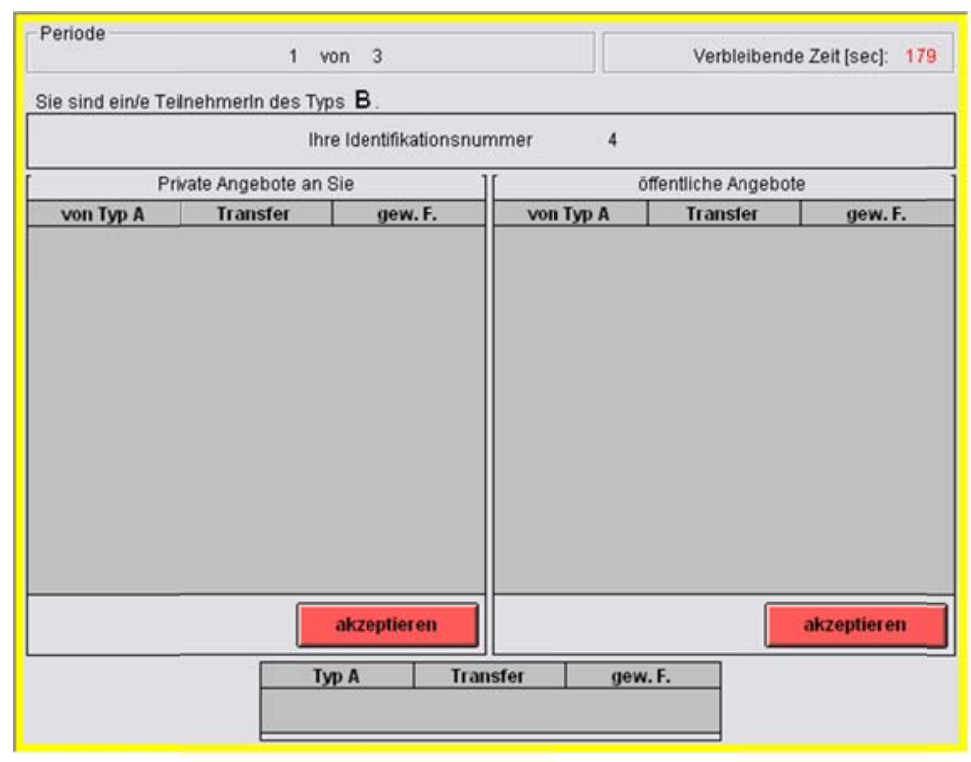

Once the above screen is displayed the trading phase has started. Participants of type B can now accept offers submitted by the type A participants. There are two types of offers which you can accept:

- Private offers

Only the Type B the offer was addressed to will be able to see and accept a private offer. No other type A or B is informed about these offers. If you receive private offers in the role of type B, they will appear on the left side of your screen, below the header "Private offers to you". The offer 
contains the following information: the identification number of the type A, who submitted the offer, the transfer which he offers and which factor he desires. To accept a private offer, a click on the respective row in which the offer is displayed marks the offer and it will be highlighted. The offer is accepted by clicking on the button "accept" at the bottom of the screen. As long as the "accept" button has not been clicked the choice can be altered.

- Public offers.

All type B participants are informed about these offers and can accept them. Public offers appear on the right side of the screen below the header "Public offers". Again, the offer contains the identification number of the type A who submitted the offer, the transfer which he offers and which factor he desires. This information is also displayed to all other participants of type A and type B. The procedure to accept public offers is the same as for private offers: A click on the respective row in which the offer is displayed marks the offer and it will be highlighted. The offer is accepted by clicking on the button "accept" at the bottom of the screen. As long as the "accept" button has not been clicked the choice can be altered.

As soon as the "accept" button is pressed the accepted offer is displayed in the bottom row of the screen.

- Once all 4 participants of type A have concluded three trades or after 3 minutes have elapsed, the trading phase is over.

- No buyer is obliged to submit offers, and no seller is obliged to accept an offer.

\section{Determining the Actual Factor}

After the trading phase, all participants of type B who have concluded a trade determine which factor they send to the type A participants. The factor desired by the type A is not binding! Type B participants can choose exactly the factor desired by type A, but also a higher or lower factor. The factor is entered in the following screen:

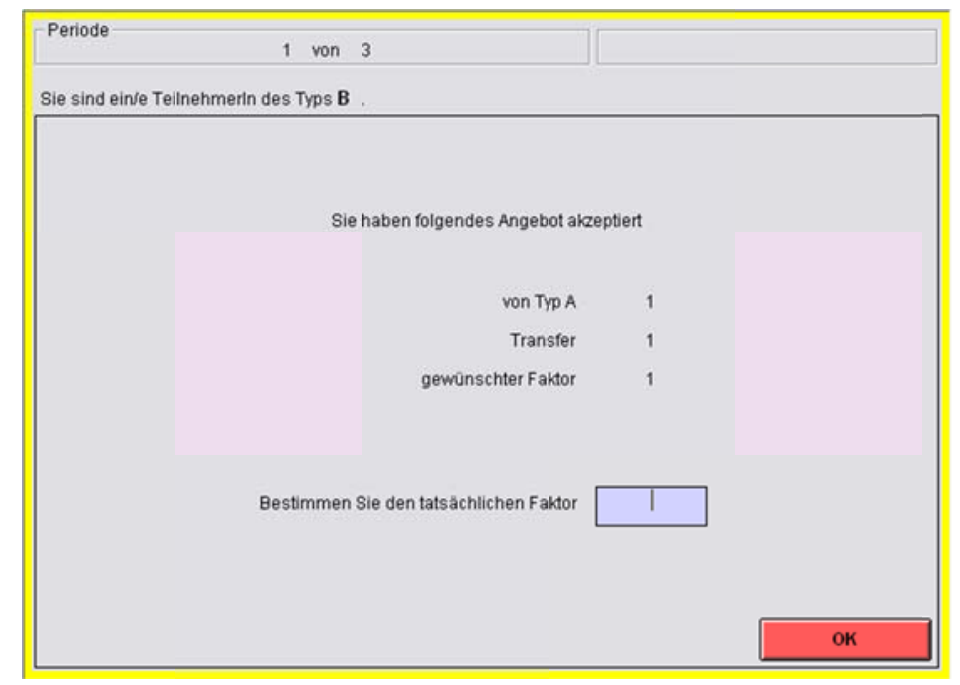

In order to determine the actual factor, enter the value for the factor in the field "Determine the actual factor". By pressing the "OK" button the choice is confirmed As long as the "OK" button has not been clicked the choice can be altered.

The desired factor is a number between 1 and 10:

$$
1 \leq \text { desired factor } \leq \mathbf{1 0}
$$

While type B is entering the factor, type A specifies on a separate screen, which factor he expects to receive, and how certain he is about these expectations.

\section{How are incomes calculated?}

\section{Income Type A:}

- If no trade was concluded, participants of type A receive an income of 0 points in that period.

- If at least one of type A's offers was accepted, the income depends on the transfer sent and on the factor chosen by type $B$. The income is calculated as follows: 
Type A receives the sum of all transfers (at most three) which are multiplied by the factor 10 . He has to pay the sum of all transfers.

As can be seen see from the above formula the income of type A is higher, the higher the factor chosen by the participants of type B. At the same time the income is higher, the lower the transfer(s).

Income Type B:

- If no trade was concluded, participants of type B receive an income of 5 points in that period.

- If type B accepted an offer, the income depends on the transfer sent and on the costs of the factor chosen by type $B$. The income is calculated as follows:

\section{Income type $B=$ transfer - costs of the factor}

The higher the chosen factor, the higher the costs. The costs for each possible factor are displayed in the table below:

\begin{tabular}{|l|l|l|l|l|l|l|l|l|l|l|}
\hline factor & $\mathbf{1}$ & $\mathbf{2}$ & $\mathbf{3}$ & $\mathbf{4}$ & $\mathbf{5}$ & $\mathbf{6}$ & $\mathbf{7}$ & $\mathbf{8}$ & $\mathbf{9}$ & $\mathbf{1 0}$ \\
\hline costs of the factor & 0 & 1 & 2 & 4 & 6 & 8 & 10 & 12 & 15 & 18 \\
\hline
\end{tabular}

The income of type B is therefore higher, the lower the factor chosen and the higher the transfer(s) received.

The income of all Type $A$ and type $B$ participants are determined in the same way. Each participant can therefore calculate his own income and the income of the players connected with him in that period. Furthermore, each participant is informed about the identification number of his trading partner in each period.

Please note that you can incur losses in each period. These losses have to be paid from the initial endowment or from earnings made in other periods.

\section{Information}

You will be informed about your income and the income of the participants connected to you on an "income screen". On this screen (see below) the following will be displayed:

- The ID(s) of the participants you concluded a trade with,

- the offered transfer,

- the desired factor,

- the actual factor chosen,

- the income of each participant involved, and

- your income in this period. 


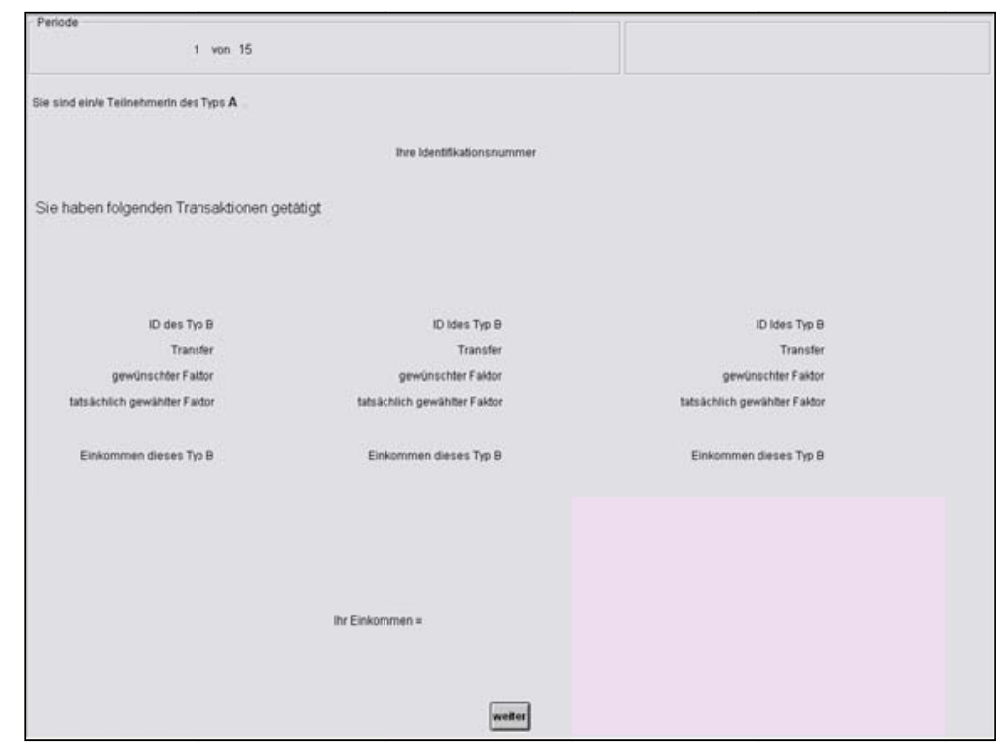

Please copy all the information into the documentation sheet at the end of this text!

After the income screen has been displayed, the period is over and the next period starts with the trading phase. When you have finished studying the income screen please click on the "continue" button.

The experiment will not start until all participants are perfectly familiar with all procedures. In order to ensure that this is the case we kindly ask you to solve the exercises on the following pages.

Additionally 2 trials of the trading phase will be conducted, so that you can get accustomed to the software. During the trial phases no money can be earned. After those trial phases the 15 periods of the experiment will start. 


\section{Control Questionnaire}

Please solve the following exercises completely. If you have questions ask the experimenter. Wrong answers will not have any effect on the experiment or your payoffs.

\section{Exercise 1}

Type $A$ did not make an offer during the trading phase. What is his income in this period?

Income type $A=$

\section{Exercise 2}

Type B did not accept an offer during the trading phase. What is his income in this period?

Income type $B=$

\section{Exercise 3:}

An offer containing a transfer 30 and a desired factor of 9 is accepted. Type $B$ chooses a factor of 9 . Income type $A=$

Income type $B=$

\section{Exercise 4:}

An offer containing a transfer 60 and a desired factor of 9 is accepted. Type $B$ chooses a factor of 6 .

Income type $A=$

Income type $B=$

\section{Exercise 5:}

An offer containing a transfer 10 a desired factor of 2 is accepted. Type $B$ chooses a factor of 5

Income type $A=$

Income type $B=$

\section{Exercise 6:}

An offer containing a transfer 40 and a desired factor of 4 is accepted. Type $B$ chooses a factor of 5 .

Income type $A=$

Income type $B=$

Exercise 7:

During the trading phase Type A made several offers. None of theses offers was accepted. What is his income in this period?

$$
\text { Income type } A=
$$

\section{Exercise 8:}

The following offers were accepted:

Trade 1: Transfer 40 desired factor 7; chosen factor 5 .

Trade 2: Transfer 40 desired factor 7 ; chosen factor 8.

Trade 3: Transfer 40 desired factor 7 ; chosen factor 4 .

$$
\begin{aligned}
& \text { Income type } B_{(\text {Trade1) }}= \\
& \text { Income type } B_{(\text {Trade2) }}= \\
& \text { Income type } B_{(\text {Trade3) }}= \\
& \text { Income type } A=
\end{aligned}
$$

When you have completed the exercises we recommend taking a second look at the exercises and the solutions provided. 